\title{
The impact of melatonin and carbon ion irradiation on cancer stem cells
}

\author{
Mu-Tai Liu ${ }^{1,2 *}$ and Russel J. Reiter ${ }^{3}$ \\ ${ }^{1}$ Department of Radiation Oncology, Changhua Christian Hospital, 135 Nan Shiau Street, Changhua 500, Taiwan \\ ${ }^{2}$ Department of Radiology, Yuanpei University of Science and Technology, 306 Yuanpei Street, Hsinchu 300, Taiwan \\ ${ }^{3}$ Department of Cellular and Structural Biology, The University of Texas Health Science Center, San Antonio, Texas 78229, USA
}

\begin{abstract}
Aim: Cancer stem cells (CSCs) exhibited an excessive migratory and invasive potential. Melatonin may inhibit multiple crucial signals associated with tumor stem cell self-renewal, viability, invasiveness, tumor growth, and therapy resistance. Carbon ion irradiation may be a promising therapeutic modality in both non-stem-like and stem-like tumor cells in contrast to photon irradiation. A comprehensive understanding of the mechanisms and molecular pathways associated with invasive properties of CSCs is essential in developing novel treatment options for cancer therapy that target CSCs.

Materials and methods: A systematic review of the existing literature was conducted using the following search terms: 'melatonin', 'X-ray irradiation', 'charged particle irradiation', 'carbon ion irradiation', 'cancer stem cells', 'tumor-initiating cells' and 'cancer stem-like cells'. The search used PubMed and spanned the period from January 2000 to December 2016.

Results: The collected data included the impact of melatonin and carbon ion irradiation on tumor stem cells. The impact of melatonin on tumor stem cells consisted of 'Melatonin inhibits tumorigenicity of brain tumor stem cells via the AKT-EZH2-STAT3 signaling axis', 'Melatonin-induced methylation of the ABCG2/ BCRP promoter overcomes multidrug resistance in brain tumor stem cells', 'Involvement of autophagy in melatonin-induced cytotoxicity in brain tumor stem cells', 'Melatonin inhibits estrogen receptor binding to estrogen response elements sites on the OCT4 gene in breast cancer stem cells' and 'Effect of melatonin in epithelial mesenchymal transition markers and invasive properties of breast cancer stem cells'. The impact of carbon ion irradiation on tumor stem cells consisted of 'Carbon ion irradiation effectively eradicates brain tumor stem cells', 'Carbon ion irradiation counteracts cancer stem cells' migration and invasion process in head and neck squamous cell carcinoma', 'Carbon ion beam combined with cisplatin effectively disrupts triple negative breast cancer stem cells', 'Effects of carbon ion beam on putative colon cancer stem cells and its comparison with X-rays' and 'Different effects of carbon ion beams and X-rays on clonogenic survival and DNA repair in human pancreatic cancer stem-like cells'.
\end{abstract}

Conclusion: Cancer stem cells possess the capacity of self-renewal and pluripotency, generating all cells within a tumor, and are responsible for tumor growth, therapy resistance and metastasis. Melatonin attenuated AKT activation, EZH2 S21 phosphorylation, EZH2-STAT3 interactions and altered histone modifications to reduce tumor initiation and propagation of brain tumor stem cells (BTSC). Melatonin increases the efficacy of chemotherapeutic agents, targeting both the tumor bulk and BTSCs through the regulation of the expression and function of the ABCG2/BCRP transporter by inducing the methylation of its promoter. Melatonin treatment induced cell death with ultrastructural characteristics of autophagy. Breast cancer stem cells (BCSCs) are responsive to melatonin treatment by way of reducing the viability and the invasiveness of breast cancer mammospheres as well as regulating the expression of OCT4, N-cadherin and vimentin proteins associated with epithelial mesenchymal transition in BCSCs. Carbon irradiation is effective in brain tumor stem cell (BTSC) elimination with relative biologic effectiveness (RBE) in the range of 1.87-3.44. Carbon ion irradiation may be a promising therapeutic modality because it reduces migration and invasion processes in both head and neck squamous cell carcinoma and cancer stem cells in contrast to photon irradiation. Low LET X-ray irradiation may essentially eradicate the non-stem-like tumor cells, consequently the radioresistant cancer stem-like cell population is obviously enriched. In contrast, carbon ion irradiation may eradicate both non-stemlike and stem-like tumor cells at the same time. Carbon ion irradiation is a promising tool to eradicate putative colon cancer stem-like cells. Further investigation to elucidate the mechanisms and molecular pathways involved in cancer stem cells particularly associated with melatonin and carbon ion irradiation certainly is warranted.

\section{Introduction}

Cancer stem cells (CSCs), also called tumor-initiating cells, comprise a distinct portion of the tumor mass that possess the capacity of self-renewal and pluripotency, generating all cells within a tumor; these specialized cells are responsible for tumor recurrence, resistance to chemotherapy and radiotherapy, and for metastasis [1-4]. Cancer stem cells are also responsible for the development of tumor cell heterogeneity which is often related to the failure of conventional therapies [5]. Therefore, targeting CSCs is critical for developing innovative therapies to counteract cancer relapse and emergence of drug resistance [6].

Melatonin (N-acetyl-5-methoxytryptamine), an indole compound synthesized by the pineal gland and many other tissues, is a critical inhibitor of tumors [7-14]. This molecule executes its anticancer effects in various types of cancer due to its pro-apoptotic, anti-proliferative, anti-cell differentiation and anti-angiogenic actions $[15,16]$. Numerous studies indicate that melatonin inhibits multiple crucial signals associated with brain tumor stem cell self-renewal, viability,

Correspondence to: Mu-Tai Liu, Department of Radiation Oncology, Changhua Christian Hospital, 135 Nan Shiau Street, Changhua, Taiwan, Tel: +886-47238595; E-mail: tomgiessen@gmail.com

Key words: Melatonin, X-ray irradiation, charged particle irradiation, carbon ion irradiation, cancer stem cells, tumor-initiating cells, cancer stem-like cells

Received: July 03, 2017; Accepted: July 31, 2017; Published: August 03, 2017 
invasiveness, tumor growth, and therapy resistance [17-19]. Melatonin not only exhibits an antitumor effects on total tumor mass but also antitumor actions on subpopulations of CSCs [21]. Radiation therapy is an imperative modality of cancer treatment. X-rays consist of photons and are commonly used in radiation therapy. X-rays are defined as low LET (Linear Energy Transfer) radiation which produce only occasional ionizations along their trajectories [22]. Failure of radiation therapy using photon irradiation is usually related to metastasis [23]. There is an increasing application of high-LET charged particles such as protons and carbon ions in the treatment of cancer [24-26]. Carbon ions create numerous ionizations along their trajectories, and induce unrepairable clustered DNA damage. Carbon ion irradiation is more potent in the induction of cytogenetic damage and cytotoxicity of irradiated cells than low-LET X-rays [26,27]. Several recent studies indicate that carbon ion irradiation may be a promising therapeutic modality because of complex DNA damage, increased apoptosis, and counteractive actions on migration and invasive processes in both parental cells of head and neck squamous cell carcinoma and CSCs that it displays. This distinguishes it from photon irradiation [28-32].

A comprehensive understanding of the mechanisms and molecular pathways associated with invasive properties of CSCs is essential in developing novel treatment options for cancer therapy that target CSCs.

\section{Materials and methods}

\section{Literature search strategy}

A systematic review of the existing literature was conducted using the following search terms: 'melatonin', 'X-ray irradiation', 'charged particle irradiation', 'carbon ion irradiation', 'cancer stem cells', 'tumor-initiating cells' and 'cancer stem-like cells'. The search used PubMed and spanned the period from January 2000 to December 2016.

\section{Inclusion and exclusion criteria}

We identified reports containing the impact of melatonin and carbon ion irradiation on tumor stem cells for inclusion. Reports which were published in languages other than English, only published in abstract form, not related to tumor stem cells, duplicate articles and those containing insufficient detail were excluded. All titles and abstracts were screened to assess whether they were eligible for inclusion. Then abstracts and full texts of all eligible studies were examined and data was evaluated.

\section{Results}

\section{Literature search results}

The search identified 109 potentially eligible articles. After application of the exclusion criteria, only10 met the criteria and were therefore evaluated. The collected data included the impact of melatonin and carbon ion irradiation on tumor stem cells. The impact of melatonin on tumor stem cells consisted of 'Melatonin inhibits tumorigenicity of brain tumor stem cells via the AKT-EZH2-STAT3 signaling axis', 'Melatonin-induced methylation of the ABCG2/BCRP promoter overcomes multidrug resistance in brain tumor stem cells', 'Involvement of autophagy in melatonin-induced cytotoxicity in brain tumor stem cells', 'Melatonin inhibits estrogen receptor binding to estrogen response elements sites on the OCT4 gene in breast cancer stem cells' and 'Effect of melatonin in epithelial mesenchymal transition markers and invasive properties of breast cancer stem cells'. The impact of carbon ion irradiation on tumor stem cells consisted of 'Carbon ion irradiation effectively eradicates brain tumor stem cells',
'Carbon ion irradiation counteracts cancer stem cells' migration and invasion process in head and neck squamous cell carcinoma', 'Carbon ion beam combined with cisplatin effectively disrupts triple negative breast cancer stem cells', 'Effects of carbon ion beam on putative colon cancer stem cells and its comparison with X-rays' and 'Different effects of carbon ion beams and X-rays on clonogenic survival and DNA repair in human pancreatic cancer stem-like cells'.

\section{The impact of melatonin on tumor stem cells}

Melatonin inhibits tumorigenicity of brain tumor stem cells via the AKT-EZH2-STAT3 signaling axis: Several studies demonstrated that glioblastoma stem-like cells (GSCs) or brain tumor stem cells exhibiting self-renewing and tumor propagating capacity play an essential role in maintaining tumor growth, therapeutic resistance, and tumor recurrence [33-35]. Polycomb group proteins are related to the development of various types of cancer [36]. Epigenetic perturbations are the possible basis for transcriptional misregulation of tumor suppressor genes. The results of this misregulation relates to the formation of cancer stem cells, which generate tumors through a combination of increased self-renewal and incomplete cellular differentiation (36). Polycomb proteins comprise at least two different complexes, the Polycomb-repressive complexes 1 and 2 (PRC1 and PRC2) [36]. Polycomb repressive complex 2 (PRC2) plays a principal role in transcriptional silencing by placing methylation marks on lysine 27 of histone H3 [37,38]. Dysregulation of PRC2 function is associated with certain malignancies and poor prognosis [37,38]. Enhancer of zeste homologue 2 (EZH2) is the catalytic subunit of PRC2. Therefore, EZH2 is regarded as an essential target for pharmacological intervention $[37,38]$. EZH2 is involved in inhibiting gene expression through methylation of histone $\mathrm{H} 3$ on lysine 27. EZH2 overexpression is associated with tumorigenesis and related to poor prognosis in various tumor types [38-40]. AKT is an oncogenic protein kinase that plays a critical role in cell transformation, cancer cell proliferation, invasion, migration, and angiogenesis of tumor tissues [41-43]. Phosphoinositide 3- kinase (PI3K)/AKT signaling is frequently overexpressesd in glioblastoma multiforme (GBM) specimens [44-48].

Chen and colleagues utilized glioblastoma stem-like cells (GSCs) isolated from surgical specimens of patients with GBM to analyze the role and underlying mechanisms associated with melatonin in GSC biology [17]. They noticed that treatment with $1 \mathrm{~mol} / \mathrm{L}$ melatonin changed the shape of neurospheres. They evaluated the effect of melatonin treatment on in vitro cell proliferation, and found that GSCs presented moderate reduction in proliferation rate as illustrated by roughly a $25 \%$ reduction in BrdU incorporation. Utilizing a clonogenic assay to estimate the effect of melatonin treatment on GSC selfrenewal, neurospheres were treated with $1 \mathrm{~mol} / \mathrm{L}$ melatonin for 5 days; the spheres were then disrupted and plated as single-cell suspensions in CSC medium to evaluate the sphere-forming ability. The clonogenic index was reduced by $>75 \%$ in all GBM samples due to melatonin treatment.

Western blotting showed that melatonin induced a decrease in expression of cancer stem cell markers. After pretreatment with luzindole, a melatonin membrane receptor antagonist, GSCs were treated with melatonin $(1 \mathrm{~mol} / \mathrm{L})$ for 5 days. CD133 expression was subsequently detected by Western blot analysis. This analysis revealed that the downregulation of CD133 by melatonin was interrupted by blockade of the melatonin membrane receptors. The data further suggested an inhibitory effect of melatonin on GSC self-renewal and tumor-initiating capacity [17]. 
EZH2-STAT3 interaction is noticeable in GSCs and necessary for GSC clonogenic growth [49-51]. Co-immunoprecipitation experiments were carried out to define the effect of melatonin treatment on EZH2STAT3 interaction in GSCs. EZH2-STAT3 co-precipitation was abundant in GSCs without melatonin treatment. In contrast, it was barely detectable in lysates isolated from GSCs following melatonin treatment [17].

Melatonin inhibited EZH2 S21 phosphorylation (pS21) in GSCs samples. Measurement of the level of H3K27me3 in GSCs treated with melatonin was carried out to ascertain the effect of melatonin-induced EZH2 pS21 on the methylation status of histone H3. Noticeable increases in $\mathrm{H} 3 \mathrm{~K} 27 \mathrm{me} 3$ in response to melatonin treatment were detected [17].

STAT3 activation is mediated by phosphorylation of EZH2 S21 and the subsequent methylation of STAT3 by EZH2 [52,53]. The role of melatonin in STAT3 methylation and its effect on GSCs was assessed. Significant inhibition of STAT3 methylation with melatonin treatment was found in all three GSCs [17]. At the same time, tyrosinephosphorylated STAT3 (pY-STAT3) concentration was reduced by $30 \%$ as compared with that detected in GSCs without melatonin treatment. A luciferase reporter assay indicated that STAT3 transcriptional activity was essentially inhibited by melatonin treatment [17].

Briefly, AKT overexpression obviously increased EZH2 S21 phosphorylation levels, EZH2-STAT3 interactions, and STAT3 activity, but reduced H3K27me3 levels [17]. The data revealed that melatonin directly targeted glioma tumor cells by modifying GSC biology and inhibiting GSC proliferation. AKT-STAT3-EZH2 signaling and EZH2 phosphorylation play essential roles in GSC growth. Melatonin treatment attenuated AKT activation, EZH2 S21 phosphorylation, EZH2-STAT3 interactions and altered histone modifications to repress tumor initiation and propagation. These results show that melatonin attenuates multiple crucial signals associated with GSC self-renewal and survival, and further suggest melatonin as an encouraging therapeutic agent for the treatment of GBM [17].

Melatonin-induced methylation of the ABCG2/BCRP promoter overcomes multidrug resistance in brain tumor stem cells: Recent studies demonstrate that brain tumor stem cells in malignant glioblastomas, which overexpress members of the adenosine triphosphate-binding cassette $(\mathrm{ABC})$ family transporters, accounts for multidrug resistance and tumor recurrence [54-56]. Thus, a therapeutic strategy that targets both the tumor bulk and the brain tumor stem cell (BTSC) compartment is essential to bring about a stable and enduring remission [18].

Martin and colleagues observed that melatonin markedly increased the cancer killing activity of temozolomide, doxorubicin or mitoxantrone [18]. Their study indicated that co-incubation of melatonin plus a chemotherapeutic drug resulted in a synergistic inhibitory action in the three BTSC lines (NSC23, NSC7-2 and NSC11) tested. BTSCs revealed much higher mRNA levels for ABCG2/BCRP and $\mathrm{ABCB} 1 / \mathrm{MDR} 1$ than in glioblastoma cell lines [18]. This finding was compatible with a higher resistance of BTSCs to temozolomide, doxorubicin and mitoxantrone. They found that melatonin induced a significant reduction in the mRNA levels of ABCG2/BCRP in BTSCs. These findings indicate that melatonin may inhibit multidrug resistance in BTSCs through the downregulation of ABCG2/BCRP expression, resulting in an increase in intracellular drug accumulation and the subsequent enhancement of cell death [18].
Martin and colleagues observed that glioblastoma samples isolated from patients had lower methylation levels in the ABCG2 promoter than the normal brain. Treatment of BTSCs with melatonin induced a significant reduction in the levels of unmethylated promoter and an accompanying increase in the levels of hypermethylation and partial methylation. Methylation-specific PCR (MSP) analysis verified the methylation of the ABCG2/BCRP promoter in BTSCs after treatment with melatonin [18]. Thus, melatonin may reduce transporter expression and BTSC resistance to chemotherapeutic drugs by inducing the methylation of the ABCG2/BCRP promoter.

These authors also reported that melatonin not only enhanced chemotherapy induced cell death in BTSCs but also in a human malignant glioblastoma cell line (A172). An elevation in promoter methylation by melatonin was inhibited by preincubation with 5 -azacitidine (AZA). This finding suggests epigenetic regulation of ABCG2/BCRP expression and function by melatonin [18].

Briefly, melatonin increases the efficacy of chemotherapeutic agents, targeting both the bulk tumor and the BTSCs through the regulation of the expression and function of the ABCG2/BCRP transporter by inducing the methylation of its promoter [18]. The data indicate a probable correlation between the downregulation of ABCG2/BCRP function and the synergistic effect of melatonin and chemotherapeutic agents. Melatonin may be a worthy candidate to counteract multidrug resistance in the treatment of glioblastomas, and consequently improve the efficacy of contemporary therapies.

Involvement of autophagy in melatonin-induced cytotoxicity in brain tumor stem cells: Glioma-initiating cells (GIC) or brain tumor stem cells are resistant to contemporary therapeutic modalities, probably accounting for the frequent tumor recurrence [33,57]. Autophagy, the process of cellular self-eating, is recognized as a lysosomal degradation pathway that plays the role of a dynamic regulator of tumorigenesis [58,59].

In the study performed by of Martin and colleagues, neurospheroid cultures were established from cells dissociated from human glioblastoma postsurgical specimens [21]. Neurospheroid cultures display a GIC phenotype (self-renewal, proliferation, expression of stem cell markers, pluripotency, and ability to form tumors in vivo). To examine the effect of melatonin on cell proliferation in GIC derived from glioblastoma patients, three GIC lines (GIC-A, GIC-B, and GIC-C) were treated with different concentrations of melatonin (1$1000 \mu \mathrm{M})$. Only the highest concentration $(1 \mathrm{mM})$ inhibited the growth of the three GIC lines [21].

For the purpose of evaluating the effect of melatonin on selfrenewal, limiting dilution assays were carried out [21]. Melatonin reduces formation of secondary spheres after dissociation. In the melatonin-treated groups, at least a doubling of cell number is required to generate a secondary neurosphere. Melatonin also reduces self-renewal capability in the clonogenic assay for the three GIC lines tested. Melatonin treatment reduces mRNA expression levels of stem cell markers such as the transcription factors Sox2, Oct3/4 and Nanog in the three GIC lines tested, implying the role of melatonin in the modulation of stem cell properties in GIC [21].

Martin and colleagues assessed the effect of melatonin on the viability of the GICs subpopulation. They found that melatonin induced a time-dependent increase in the lactate dehydrogenase (LDH) release starting at 48 hours after treatment which pointed out an induction of cell death. The effect of melatonin on the viability of a normal human 
neural cell line (hNSC.100) was likewise assessed. No significant change in $\mathrm{LDH}$ release at any time point was found, indicating that the cancer killing effect of melatonin is limited to cancer-derived stem cells [21].

These authors further examined the ultrastructural characteristics of GIC after melatonin treatment to determine the nature of the effect of melatonin on these cells. Cells treated with melatonin revealed a progressive accumulation of autophagosome vacuoles starting at 24 hours after treatment. Vacuoles enclosed cytoplasmic content and were more numerous with increased treatment time. Consequently, at a later stage after melatonin treatment, vacuoles occupied a major part of cytoplasm and an immense disruption of the cellular membrane associated with an extremely vacuolated cytoplasm and disruption of structures in the cell were found. Melatonin induction of autophagy in GIC was also validated by Western blot. Treatment with melatonin enhances conversion of microtubule-associated protein 1A/1B-light chain 3 (LC3 I) to LC3 II, which suggested initiation of autophagy cascade and formation of autophagosomes [21].

Briefly, the study of Martin and colleagues showed that melatonin treatment reduced GIC proliferation and caused a reduction in selfrenewal and clonogenic capability which coexisted with a reduction in the expression of stem cell markers. Furthermore, the study also indicated that melatonin treatment induced cell death with ultrastructural characteristics of autophagy. Melatonin not only presents an antitumor effect on bulk tumor cells but also exhibits antitumor actions on the GIC subpopulation. Accordingly, the results indicate that melatonin could be a promising therapeutic agent in the treatment of glioblastoma.

Melatonin inhibits estrogen receptor binding to estrogen response elements sites on the OCT4 gene in human breast cancer stem cells: The transcription factor OCT4, encoded by the POU5F1 gene, is a crucial factor for self-renewal and maintenance of pluripotency of cancer stem cells [60-62]. Estradiol (E2) is the principal growth stimulant of estrogen receptor (ER) positive breast tumors $[63,64]$. Bisphenol A (BPA) is an environmental estrogen with analogous biological functions of E2. BPA plays a role in the initiation or progression of breast cancer and activates the transcription of genes which promote the proliferation of the breast cancer cells $[65,66]$. Lopes and colleagues assessed the effect of melatonin on the regulation of OCT4/POU5F1 in breast cancer stem cells (BCSC) after activation with tumor initiation chemical BPA and E2 in MCF7 cells. Two individual techniques, cell suspension and anchorage independent growth, of three-dimensional growth of mammospheres were utilized [20]. The growth in a three-dimensional (3D) model provides an artificial tumor environment where the cells segregate appropriately to form components of adult tissues comparable to the situation found in vivo $[67,68]$. Both techniques were carried out to assess the effect of melatonin on mammospheres treated with BPA and E2. The results of both techniques were similar. The treatment with $10 \mathrm{nM}$ E2 or $10 \mu \mathrm{M}$ BPA significantly increased the number and the size of the mammospheres as compared with the control group. On the contrary, $1 \mathrm{mM}$ of melatonin significantly reduced the number and size of mammospheres as compared with the control. Moreover, when the cells were stimulated by E2 or BPA and treated with melatonin simultaneously, there was an obvious reduction in the number and size of mammospheres [20].

The chromatin immunoprecipitation assay was carried out to determine the effect of melatonin on estrogen receptor binding to the POU5F1 gene. Mammospheres treated with $10 \mathrm{nM}$ E2 or $10 \mu \mathrm{M}$ BPA markedly increased the binding of ER to the putative ERE (estrogen response element) sequences in OCT4 transcription site OCT4-3544. On the contrary, the cells stimulated by $10 \mathrm{nM} \mathrm{E} 2$ or $10 \mu \mathrm{M}$ BPA and treated with $1 \mathrm{mM}$ melatonin revealed a significant lowering in the binding of ER to the putative ERE sequences in OCT4 transcription site OCT4-3544. Moreover, mammospheres treated with E2 or BPA slightly enhanced the binding of ER to ERE sites at $-1999 \mathrm{~kb}$ of OCT4 promoter region. This enhancement was reduced when mammospheres were treated with melatonin [20].

Quantitative real time PCR ( $\mathrm{qPCR}$ ) was conducted to examine the OCT4 and ERa gene expression levels after E2 and BPA treatment with or without melatonin. Cells treated with E2 or BPA exhibited increased levels of transcript for OCT4 and ER $\alpha$ genes. Levels of OCT4 and ER $\alpha$ mRNA were remarkably decreased in cells treated with melatonin alone, or simultaneous treatment with either E2 or BPA [20].

The effect of estrogen, BPA and melatonin on ER and OCT4 protein levels in these cells was evaluated. E2 and BPA markedly stimulated levels of ERa protein. OCT4 protein levels were also enhanced in cells treated with E2 or BPA. ERa protein levels were decreased in all cells treated with melatonin, but the extent of the reduction was not precisely related to the changes in mRNA levels, indicating that additional levels of regulation probably influenced ERa levels. In addition, melatonin reduced the levels of OCT4 protein. Only minimal changes in OCT4 transcript levels were noticed, implying that the regulation of protein levels of OCT4 may be modulated at a translational and/or posttranslational level [20].

In summary, the study of Lopes and colleagues demonstrated that melatonin inhibited the effects of E2 and BPA treatment on mammosphere growth together with the expression of ER $\alpha$ and the stem cell marker OCT4. Melatonin treatment is effective in inhibiting the proliferation of BCSC and exerts an influence on the ER pathway, indicating it may be useful as a therapy in breast cancer.

Effect of melatonin in epithelial mesenchymal transition markers and invasive properties of breast cancer stem cells: The epithelial mesenchymal transition (EMT) is a process that allows cancer stem cells to become invasive and metastatic [69-71]. This process is mediated by the activity of growth and transcription factors, leading to loss of the intercellular junction structure of epithelial cells, obtaining a mesenchymal morphology, loss of apical-basal cell polarity and migration/invasion capability [72-74]. Various investigations have also indicated that EMT is involved in cell plasticity, the process by which non-stem cells acquire stem cell characteristics [75-77]. The principal EMT molecular features include loss of the epithelial marker E-cadherin, and overexpression of mesenchymal markers N-cadherin and vimentin [78,79]. Various studies also indicate that melatonin has anti-invasive and anti-metastatic effects, which involve multiple cellular processes including EMT [80-82].

A number of studies demonstrated the existence of stem cells in canine and human breast cancer cell lines [83-89]. The study of Dontu and colleagues demonstrated that the stemness of tumor cells is assessed in vitro by their capability to produce mammospheres [90]. Canine and human breast cancer cells readily produced mammospheres, and include CD44+/CD24low/- cells, which verify the cancer stem cell phenotype [90]. Breast cancer cells with CD44+/ CD24low/- surface phenotype possessed tumor initiating features with pluripotency properties and invasive capability [19]. Ponti and colleagues observed that a breast cancer cell line that developed into spheroids also had CD44+/CD24low/- phenotype and expressed the transcription factor OCT4 [91]. The expression of OCT4 has an 
essential role in carcinogenesis and offers a probable mechanism by which cancer cells obtain or sustain the therapy resistance phenotype $[92,93]$. Moreover, overexpression of this gene was related to metastasis and poor prognosis in various types of cancer, including colorectal, lung and gliomas [94-99].

In the study of Goncalves and colleagues, mammospheres were generated from the canine mammary cancer cell line CMT-U229 and human breast cancer cell line MCF-7 in MammoCultTM medium (StemCell Technologies). The MTT (3-(4,5-dimethylthiazol-2-yl)2,5-diphenyltetrazolium bromide) assay was performed to estimate the number of viable cells after the treatment with $1 \mathrm{mM}$ melatonin for 24 hours. Cell viability from mammospheres of both cell lines was significantly reduced after treatment with $1 \mathrm{mM}$ melatonin for 24 hours as compared with control groups [19]. To assess the effects of melatonin on breast cancer stem cells from both cell lines, the protein expression of the cancer stem cell marker OCT4, the epithelial marker E-cadherin, the mesenchymal markers $\mathrm{N}$-cadherin and vimentin, were estimated in cells from mammospheres. In CMT-U229 cells treated with $1 \mathrm{mM}$ of melatonin, OCT4 protein expression was significantly reduced compared to the control group and E-cadherin protein expression was significantly enhanced after melatonin treatment compared to the control group. $\mathrm{N}$-cadherin and vimentin protein expression were markedly reduced in the melatonin treated cells compared to the controls. Regarding MCF-7 cells, OCT4 protein expression was also lowered in melatonin treated cells compared to the controls $(p=0.0001)$ and E-cadherin protein expression increased after melatonin treatment $(\mathrm{p}=0.0001)$. Low expression of $\mathrm{N}$-cadherin and vimentin proteins was found in melatonin treated cells. The assessment of cell migration and invasion was performed in Boyden Chamber. CMT-U229 and MCF-7 cells were treated with $1 \mathrm{mM}$ of melatonin for 24 hours. Melatonin reduced migration and invasion of CMT-U229 and MCF-7 mammospheres as compared with the control groups $(\mathrm{p}=$ $0.0017, \mathrm{p}=0.0377$, respectively) [19]. The results collectively reveal that canine and human breast cancer stem cells are responsive to melatonin treatment with a reduction of viability and the invasiveness of breast cancer mammospheres as well as the expression of stem cell and EMT markers, indicating the potential therapeutic role of melatonin in the treatment of breast cancer.

\section{The impact of carbon ion irradiation on tumor stem cells}

Carbon ion irradiation effectively eradicates brain tumor stem cells: The capability of cells to survive radiation and generate colonies is associated with tumor radiosensitivity. Clonogenic survival assays have assessed radiosensitivity and establish predictive models for treatment result $[100,101]$. In the study of Chiblak and colleagues, human primary glioma stem cells (GSC or brain tumor stem cells) spheroid cultures were established from tumor specimens of six consenting glioblastoma patients [28]. Human U87MG was utilized as a conventional glioblastoma radioresistant cell line. NCH601, NCH620, NCH644, NCH441, NCH421k, and NCH636 primary cell lines were cultured as neurospheres employing serum-free cancer stem cell medium. The authors developed a setting by which tumor stem cells were grown under serum-free conditions in a semi-solid 3D matrix, offering an environment that maintained the stem cell-like characteristics. Using the XRAD320 X-ray device (Precision X-Ray, North Branford, CT), these cells were irradiated at 0-, 2-, and 4-Gy photon at $320 \mathrm{KeV}$. Particle irradiation with proton and carbon ion was performed using a pencil beam in a spread-out Bragg peak with $1.5 \mathrm{~cm}$ width equivalent to a depth of $14.0 \mathrm{~cm}$ in water. Beam energies were up to a maximum of $221 \mathrm{MeV} / \mathrm{u}$ for protons and $430 \mathrm{MeV} / \mathrm{u}$ for carbon ions [102-104]. After irradiation of GSC with 0-, 2-, and 4-Gy photon, survival fraction (SF) was examined in a 2-step process. At first colonies were initially manually counted. Sphere-like colonies were counted using microscopy 2 weeks after irradiation. Two response patterns of GSC were observed after irradiation with increasing doses. NCH644 and NCH421k were most resistant to photon, with $40-50 \%$ SF2GyX and 20-25\% SF4GyX. On the contrary, survival of NCH441, NCH663, NCH620, and NCH601 was reduced by increasing doses, with SF2GyX values ranging between $3 \%$ and $17 \%$, and SF 4 GyX values ranging between $0.5 \%$ and $2 \%$.

Subsequently, the four photon radioresistant GSCs (ie, NCH644, NCH421k, NCH441, NCH636) and human U87MG GBM cells were irradiated at 4-Gy photon, proton, or carbon. Cell survival was assessed by measuring fluorescence. The data revealed NCH644 (SF4GyX 87\%, $\mathrm{P}<0.137)$ and NCH421k (SF4GyX $81 \%, \mathrm{P}<0.0001)$ as the two most photon-resistant GSCs, with a radioresponsiveness similar to that of U87 (SF4GyX 80\%, P<0.023). Irradiation of GSCs and U87 with 4-Gy proton resulted in only a slight decrease in survival compared with photon irradiation. Carbon ion irradiation at an isodose of $4 \mathrm{~Gy}$ demonstrated conspicuous cell killing as revealed by the highest survival reduction. Clonogenic survival for proton irradiation demonstrated that relative biologic effectiveness (RBE) was in the range of 0.7-1.20. Nevertheless, carbon irradiation made the photon-resistant GSC cultures sensitive, with RBE in the range of 1.87-3.44.

Radioresistance of GSCs was partly due to DNA repair proficiency compared with non-GSCs $(33,105)$. As compared with photon irradiation, a higher percentage (2.4-fold) of GSCs stained positive for nuclear $\gamma$-H2AX 24 hours after carbon ion irradiation, demonstrating residual unrepaired double-strand breaks. Likewise, carbon ion irradiation increased persistent $\gamma-\mathrm{H} 2 \mathrm{AX}$ foci as compared with photon irradiation in putative pancreatic stem cells $(32,106)$. These results indicate that the sensitivity of cancer stem cells to carbon ions might exhibit an impaired capability of GSCs to repair carbon ion-induced DNA double-strand breaks. Carbon irradiation is effective in GSC elimination with RBE in the range of 1.87-3.44. The study indicates that carbon ion radiation therapy may constitute a therapeutic approach for treatment of glioblastoma.

Carbon ion irradiation counteracts cancer stem cells' migration and invasion process in head and neck squamous cell carcinoma (HNSCC): Approximately two-thirds of patients with head and neck squamous cell carcinoma (HNSCC) exhibit an advanced stage disease at diagnosis [107-109]. Combined modality therapy consists of surgery and radiotherapy with or without chemotherapy or molecular targeted therapy [110-112]. No matter what the therapeutic intervention, however, HNSCC is still associated with a high rate of recurrence $[113,114]$. In addition, metastatic disease remains the principal cause of death in cancer $[115,116]$. Cell migration and invasion are fundamental steps of the metastatic phenomenon [117,118]. Moncharmont and colleagues reported that migration and invasion were significantly increased by a 2 Gy photon irradiation in head and neck squamous cell carcinoma cells derived from a recurrent laryngeal cancer (SQ20B cells) [29]. Enhancement of migration by photon radiation had been previously reported in several studies $[119,120]$. After photon radiation, EGFR is activated by cellular stress induced by radiation $[121,122]$. EGFR enhancement could be related to activation of intracellular signaling pathways, resulting in the secretion of matrix metalloproteases (MMP) $[121,123,124]$.

A subpopulation of cancer cells, the cancer stem cells (CSCs), exhibit excessive migratory and invasive potential $[125,126]$. These 
cells are present in HNSCC, and overexpress CD44 and aldehyde dehydrogenase $(\mathrm{ALDH})$ proteins, which are currently regarded as HNSCC CSCs' markers [127-129]. Moncharmont and colleagues reported that consecutive cell sorting was performed to isolate SQ20B/ CSCs from SQ20B parental population utilizing Side Population (SP). SQ20B/CSCs migration and invasion capacities were greater than SQ20B parental cells in basal conditions. These capacities are related to their mesenchymal phenotype with presentation of a high $\mathrm{N}$-cadherin expression and a low E-cadherin expression [29]. These phenotypic characteristics are similar to those reported in other studies where CSCs present a mesenchymal phenotype [130,131]. The aggressive charateristics (high migratory and invasive potential) of cancer stem cells (CSCs) in head and neck squamous cell carcinoma may explain their resistance to conventional chemotherapy and radiotherapy [29]. Various means to improve local control and long-term survival in advanced SCCHN have been implemented [132,133].

EGFR inhibition plays an essential role in decreasing tumor cell repopulation by modulation of cellular proliferation and enhancement of radiosensitivity of the tumor $[134,135]$. Cetuximab, a chimerized immunoglobulin G1 monoclonal antibody against the ligand-binding domain of EGFR, inhibits the tyrosine kinase activity of EGFR and increases the cytotoxic effects of radiation in squamous-cell carcinoma [136,137].

Beuve and colleagues reported that high linear energy transfer (LET) radiation induces a twofold increase in relative biological effectiveness (RBE) compared to that of photon radiation [138]. Mizoe and colleagues demonstrated that carbon ion irradiation was effective in the treatment of malignant melanoma and adenoid cystic carcinoma of the head and neck $[139,140]$.

Moncharmont and colleagues observed that 2 Gy photon irradiation failed to inhibit cell proliferation of SQ20B cells and SQ20B/CSCs. Treatment with cetuximab or combined treatment with cetuximab and photon irradiation reduced SQ20B proliferation. No reduction of SQ20B/CSCs proliferation was noted. The calculated SF2 of SQ20B was significantly decreased with cetuximab ( 0.81 vs 0.62 without or cetuximab, respectively, $\mathrm{p}=0.007$ ) in contrast to SQ20B/ CSCs ( 0.77 vs 0.73 , with and without cetuximab, $\mathrm{p}=0.62$ ). Carbon ion radiation decreased the survival fraction of SQ20B and SQ20B/ CSCs, with a relative biologic effectiveness (RBE) at $10 \%$ survival of 1.6 and 1.8 , respectively. The combination of carbon ion radiation with cetuximab completely inhibited migration and invasion in SQ20B cells ( $\mathrm{p}<0.01$ and $\mathrm{p}<0.005$, respectively). Cetuximab was without effect on the survival fraction of SQ20B/CSCs. Migration of SQ20B/ CSCs was significantly reduced by carbon ion radiation $(\mathrm{p}<0.05)$. A significant reduction of the invasion in SQ20B/CSCs subpopulation was observed after the combined therapy with carbon ion irradiation and cetuximab $(\mathrm{p}<0.005)$ [29].

These results demonstrate the existence of a subpopulation of head and neck cancer stem cells characterized by high migratory and invasive capacities, low EGFR expression and resistance to cetuximab, which could account for the local recurrence and distant metastasis in HNSCC after conventional treatment. Carbon ion irradiation seems to be a promising therapeutic modality because it reduces the migration and invasion processes in both head and neck squamous cell carcinoma cells and cancer stem cells in contrast to photon irradiation.

Carbon ion beam combined with cisplatin effectively disrupts triple negative breast cancer stem-like cells in vitro: Triple-negative breast cancers (TNBC), why tumors that are negative for estrogen receptor (ER), progesterone receptor (PR) and human epidermal growth factor receptor 2 (HER2) exhibit invasive behavior, poor prognosis and have few targeted therapies [141,142]. Breast cancer stem-like cell (BCSC) populations have recently been recognized on the basis of the cell membrane markers CD44+/CD24-/ ESA+ cells $[143,144]$. BCSCs present the capacity for self-renewal and multilineage differentiation, tumorigenicity, and chemotherapy and radiotherapy resistance, features that account for tumor progression, disease recurrence, and metastasis [145,146]. Thus, the development of innovative CSC targeting therapeutics is critical $[147,148]$.

Heavy ion beams present a specific range and minor scatter in tissues with well-localized energy deposition at the end of the beam path; this is referred to as the "spread-out Bragg peak (SOBP)", a distinctive physical feature of charged particle beams. This results in the release of tremendous amount of energy at the end of their range. Accordingly, these ion beams bring about more cell cycle- and oxygenation-independent, irreparable DNA damage and eradicate more resistant cancer cells than conventional radiation $[149,150]$. Recently, a phase I clinical trial of early stage breast cancer treated with heavy ion irradiation noticed a limitations of dose escalation owing to adverse effects of skin, ribs, and lungs after carbon ion radiotherapy, particularly for some aggressive subtypes of breast cancer such as TNBC [30,151]. The authors considered that carbon ion beam combined with chemotherapy might decrease the dose of irradiation but preserve certain advantages to eliminate breast cancer [30,151]. The combination of chemotherapy with heavy ion radiotherapy might open new means to counteract this challenging breast cancer subgroup which has poor prognosis and highly limited treatment choices.

Sai and colleagues investigated the effects of a carbon ion beam alone or in combination with CDDP on triple negative (TN) BCSCs survival, DNA repair, and variations of in the expression of various genes compared to that of X-ray irradiation. Human TNBCSCs isolated from MDA-MB-231 and MDA-MB-453 cells were treated with carbon ion or X-ray irradiation alone or in combination with CDDP. Colony, spheroid and tumor formation assays, RT-PCR array analysis of gene expression, and immunofluorescence $\gamma \mathrm{H} 2 \mathrm{AX}$ foci assay were carried out subsequently [30].

The colony, spheroid formation, and tumorigenicity assays verified that CD44+/CD24- and ESA+/CD24- cells presented CSC properties. The percentage of CD44+/CD24- cells increased dose dependently after $\mathrm{X}$-ray irradiation, while no substantial changes were observed after carbon ion irradiation with equivalent dose of $\mathrm{X}$-ray. The proportion of CD44+/CD24- cells increased substantially when X-ray combined with CDDP compared to that of carbon ion beam with CDDP. The RBE values estimated at the D10 level for CSCs were approximately 2.14, whereas those for non-CSCs were roughly 1.78 . These data indicate that the carbon ion beam is more effective in eliminating CSCs [30].

The number of colonies formed of both CSCs and non-CSCs was remarkably decreased when carbon ion beam was combined with 25 $\mu \mathrm{M}$ of CDDP compared to carbon ion beam alone or X-ray combined with CDDP. Likewise, tumor spheroid formation of cancer stem like CD44+/CD24- cells sorted from MDA-MB-231 cells was significantly reduced after carbon ion beam irradiation compared to that following $\mathrm{X}$-ray irradiation; these were further reduced when the carbon ion beam was combined with CDDP. Spheroid formation ability of ESA+/ CD24- cells sorted from MDA-MB-453 was substantially inhibited by carbon ion beam alone but not X-ray, and it was markedly suppressed by the combination of carbon ion beam irradiation with CDDP [30]. 
RT-PCR array analysis of multiple gene expression variations in radioresistant CSCs (CD44+/CD24- cells) sorted from MDA-MB-231 cells revealed that treatment with a carbon ion beam combined with $25 \mu \mathrm{M}$ of CDDP for 5 days significantly elevated the expression of apoptosis-related cytochrome c, and had substantially increased Bax and autophagy-related genes LC3 compared to X-ray, cisplatin alone or $\mathrm{X}$-ray combined with cisplatin. These findings document that carbon ion beam treatment combined with CDDP may have a greater effect in inducing multiple cell death. Moreover, expression of CSC markers, CD44 and ESA, were nearly eliminated by carbon ion beam combined with CDDP, while X-ray, CDDP alone or X-ray combined with CDDP significantly increased the expression of ESA. Furthermore, expressions of angiogenesis- and metastasis-related genes such as HIF1 $\alpha$ and CD26 were remarkably inhibited by carbon ion beam combined with CDDP, while cisplatin alone or X-ray combined with CDDP significantly increased the expression of HIF1a and CD26. Thus, carbon ion beam irradiation in combination with CDDP may be highly effective in inhibiting tumor angiogenesis and metastasis.

The immunofluorescence assay showed that a high number of $\gamma \mathrm{H} 2 \mathrm{AX}$ foci formed at 1 hour after a carbon ion beam, X-ray alone, and in combination with CDDP further increased the number of $\gamma \mathrm{H} 2 \mathrm{AX}$ foci in CD44+/CD24- cells sorted from MDAMB-231cells. Nevertheless, at $24 \mathrm{~h}$ after carbon ion irradiation, the induced $\gamma \mathrm{H} 2 \mathrm{AX}$ foci level persisted at a level significantly higher than that in X-ray irradiated cells with an equal dose. Carbon ion beam in combination with cisplatin markedly elevated the number of $\gamma \mathrm{H} 2 \mathrm{AX}$ foci compared to carbon ion beam, $\mathrm{X}$-ray, cisplatin alone or X-ray combined with cisplatin. Additionally, not only was there a noticeable rise in the number, but also in the size, of foci (clustered DSB) commonly found in carbon ion beam exposure combined with cisplatin-treated cells compared to carbon ion beam, $\mathrm{X}$-ray, cisplatin alone or X-ray combined with cisplatin-treated cells. By means of the immunofluorescence assay, the number and size of nuclear $\gamma \mathrm{H} 2 \mathrm{AX}$ foci formed in CSCs (ESA+/CD24- cells) sorted from MDA-MB-453 cells at $24 \mathrm{~h}$ after a carbon ion beam, X-ray alone or in combination with $25 \mu \mathrm{M}$ of CDDP revealed that a much larger abundance of $\gamma \mathrm{H} 2 \mathrm{AX}$ foci persisted after carbon ion beam combined with CDDP [30].

These findings demonstrate that principal effects of carbon ion beam in combination with CDDP on TNBC cell killing primarily result from effective elimination of radioresistant TNBCSCs. The combined use of carbon ion irradiation with CDDP provides strong evidence for targeting TNBCSCs because of the complex DNA damage, increased apoptosis, autophagy, and subsequent cell death compared to conventional X-ray or carbon ion irradiation alone.

Effects of carbon ion beam on putative colon cancer stem cells and its comparison with X-rays: Colorectal cancer (CRC) is the third most common cancer worldwide and the second leading cause of cancer-related deaths in developed countries [152,153]. Complete resection of the tumor is the exclusively curative treatment modality for localized colon cancer. Nevertheless, treatment outcome for locally advanced colon cancer remains discouraging despite recent advances in surgery with adjuvant therapy $[154,155]$. Accordingly, it is imperative to investigate innovative treatment strategies for the purpose of finding a solution to the problems of discouraging treatment consequences resulting from tumor invasion to contiguous tissues, widespread metastasis, and resistance to chemotherapy and radiotherapy.

Because heavy-ion radiotherapy possesses clear advantages in treating various human radioresistant tumors, Cui and colleagues hypothesized that heavy ion irradiation may efficaciously target cancer stem cells. They investigated whether heavy-ion irradiation may have advantages over X-rays in targeting human colon cancer stem-like cells [31]. The colon adenocarcinoma cell lines HCT116 and SW480 were acquired from American Type Culture Collection. For assays of clonogenicity and ability to grow as "tumor spheres" in suspension, HCT116 and SW480 cells were isolated to obtain populations of CD133++and CD133- , CD44+/ESA+ and CD44- /ESA-cells by BD FACSAria (Becton Dickinson). The initial energy of the carbonion beams was $290 \mathrm{MeV} / \mathrm{n}, 50 \mathrm{KeV} / \mathrm{mm}, 6-\mathrm{cm}$ SOBP. The energy of heavy-ion beams at the irradiation site was obtained by comparing the calculated and measured depth-dose distribution [31].

The HCT116 and SW480 cells were irradiated with carbon ion or X-rays up to $6 \mathrm{~Gy}$, and their survival fraction was measured based on colony formation. The surviving fractions for the HCT116 and SW480 irradiated with X-rays and carbon ions caused exponentially reductions with increasing doses. Based on the survival curves, the RBE values calculated by the D10 is about 1.63 to 1.74 for carbon ion beams. After the isolation of CD133+, CD44+/ESA+ cells from the HCT116 and SW480 cells, respectively, CD133+, CD44+/ESA+ cells exhibited higher clonal and spheroid formation capacities in vitro and vigorous tumorigenicity in a xenograft model. The data implied that CD133+, CD44+/ESA+ cells exhibited the characteristics of cancer stem-like cells [31].

FACS (fluorescence-activated cell sorting) analyses revealed that the percentage of cancer stem-like cells with positive CD133, ESA, and CD44 was more enriched after X-ray irradiation compared with carbon ion irradiation. The percentage of CD133+/ CD44+ and ESA+/ CD44+cells were enriched 2- to 3-fold after irradiation with 2 or 4 Gy $\mathrm{X}$-rays. Conversely, the percentage of CD133+/ CD44+ and ESA+/ $\mathrm{CD} 44+$ cells reduced or remained stationary after 1 or 2 Gy carbon ion irradiation [31].

The surviving fractions for the cancer stem-like cells sorted from HCT116 or SW480 cell lines after irradiation with X- rays and carbon ions were reduced exponentially with increasing doses. Based on the survival curves, the RBE values calculated at the D10 level for cancer stem-like cells were about 2.05 to 2.28 , while RBE values for noncancer stem-like cells were about 1.22 to 1.44 . Judging from the tumor growth delay, the RBE values of $50 \mathrm{keV} / \mathrm{mm}$ carbon ion at the middle of a 6-cm SOBP relative to X-ray were calculated as 3.05 to 3.25 [31].

Histopathologic alterations of xenograft tumors after irradiation with X-rays or carbon-ion beams for 4 weeks were examined by H\&E staining. Histopathologic features revealed that majority of the tumor cells were not disrupted by $15 \mathrm{~Gy}$ X-rays or $5 \mathrm{~Gy}$ carbon ion irradiation. Fifteen Gy carbon ion irradiation primarily induced colon cancer cell cavitations, fibrosis and total disruption of the duct-like architecture. On the contrary, $30 \mathrm{~Gy} \mathrm{X}$-ray irradiation merely incompletely destroyed colon cancer cells while the duct-like architecture was preserved. These findings revealed that nearly all of the tumor cells were eliminated after 30 Gy carbon ion irradiation [31].

In vivo FACS analyses showed that the percentage of CD133+/ ESA+ cancer stem-like cells increased 1 month after 15 and/or 30 Gy $\mathrm{X}$-ray irradiation. Nonetheless, these cancer stem-like cells significantly reduced 1 month after 60 Gy X-ray irradiation. In contrast, 15 Gy of carbon ion irradiation did not alter the percentage of the cancer stemlike cells, while $30 \mathrm{~Gy}$ of carbon ion irradiation markedly lowered the percentage of cancer stem-like cells [31].

The findings verify that low LET X-ray irradiation may essentially eradicate the non-stem-like tumor cells, consequently the radioresistant 
cancer stem-like cell population is obviously enriched. By comparison, carbon ion irradiation eradicates both non-stem-like and stem-like tumor cells; subsequently, the proportion of cancer stem-like cells was slightly increased or remained stationary. Briefly, carbon ion irradiation is a promising therapeutic modality because of its improved targeting of putative colon cancer stem-like cells.

Different effects of carbon ion beams and X-rays on clonogenic survival and DNA repair in pancreatic cancer stem-like cells: Pancreatic cancer represents approximately 3\% of newly diagnosed cancers annually worldwide and is the fourth leading cause of cancerrelated deaths in the United States and Europe [156-158]. It is an aggressive disease. Despite recent advances in treatment, it remains a fatal malignancy and the 5-year overall survival (OS) rate does not exceed 5\% [156,157,159]. The cell surface markers CD44, CD24, and epithelial-specific antigen (ESA) have been reported as markers for detecting pancreatic cancer stem cells. CD44+CD24+ESA+ pancreatic cancer cells display the stem cell characteristics of self-renewal, the capability to produce differentiated progeny, and enhanced expression of the molecules which are essential in developmental signaling pathways $[160,161]$.

Radiotherapy is commonly used for cancer therapy and depends on ionizing radiation -induced DNA damage, especially the induction of DNA double strand breaks (DSBs). Phosphorylation of H2AX is a sensitive marker for detection of radiation-induced DSB [162,163]. The number of radiation induced $\gamma \mathrm{H} 2 \mathrm{AX}$ foci is closely related to the number of DSB $(164,165)$. Slowly repaired or unrepaired DSB may account for cell death $[32,166]$. Carbon ion irradiation is regarded as a more effective therapy than X-ray irradiation owing to the high RBE, the lack of the oxygen effect, and less cell cycle-related radiosensitivity $[32,167]$. Furthermore, some studies have demonstrated that DSBs induced by heavy ion irradiation are repaired with slow kinetics compared to those induced by photon irradiation [168].

Cancer stem-like cells sorted from human pancreatic cancer cell lines, MIA PaCa-2 and BxPc- 3 cells, were cultured with serum-free culture medium. These cells were treated with and without carbon ion or X-ray irradiation, and then colony, spheroid, tumor formation assays together with $\gamma \mathrm{H} 2 \mathrm{AX}$ foci formation assay were carried out [32]. CD44+/CD24+ cells had significantly higher clonal formation capability than that of CD44-/CD24- cells. The ability to form spheroid bodies in CD44+/CD24+ cells was noticeably higher than that in CD44-/CD24- cells. The tumorigenicity of CD44+/CD24+ cells was also much higher than that of CD44-/CD24- cells. The data indicate that CD44+/CD24+ cells isolated from MIA PaCa-2 and BxPc-3 cells exhibited the characteristics of cancer stem-like cells [32].

The surviving fractions for the MIA PaCa-2 and $\mathrm{BxPc}-3$ cells irradiated with X-rays and carbon-ion beams declined exponentially with increasing doses. The RBE values calculated at the D10 level, were 1.85-2.10 for carbon-ion beams. The surviving fractions for the cancer stem like cells isolated from the two cell lines after irradiation with $\mathrm{X}$-rays and carbon-ion beams declined exponentially with increasing doses. The RBE values calculated at the D10 level for cancer stem-like cells were 2.0-2.19. The number of tumor spheroid formations was significantly lower in carbon ion irradiated cancer stem-like cells sorted from both cell lines compared to that of X-ray irradiated cells. A high number of $\gamma \mathrm{H} 2 \mathrm{AX}$ foci formed at 1 or 6 hours after X-ray or carbon ion irradiation was observed both in CD44+/CD24+ and CD44-/CD24cells. Nevertheless, at 24 hours after carbon ion irradiation, the $\gamma \mathrm{H} 2 \mathrm{AX}$ foci level persisted at a significantly higher level than that of X-ray irradiated cells. A remarkable increase in the size of foci (clustered
DNA damage) was exclusively found in carbon-ion beam irradiated cells. Furthermore, the number of $\gamma \mathrm{H} 2 \mathrm{AX}$ foci formed in $\mathrm{CD} 44+1$ CD24+ cells declined more markedly than in CD44-/CD24- cells after X-ray irradiation, suggesting that CD44+/CD24+ cells possess an increased capability to repair X-ray-induced DSBs, which is probably a principal contributor to their greater degree of radioresistance [32].

The percentage of cancer stem-like CD44+/CD24+ cells was more enriched after X-ray irradiation compared to carbon ion irradiation. The percentage of cancer stem cell-like CD44+/CD24+ cells (in MIA PaCa-2 and BxPc-3 cells) rose markedly by 3- to 6-fold after X-ray irradiation, while the percentage of these cells merely doubled in MIA PaCa- 2 cells or decreased in BxPc-3 cells after carbon ion irradiation. The data indicate that cancer stem cell-like CD44+/CD24+ cells may be resistant to X-ray causing selective killing of non-cancer stem celllike CD44-/CD24- cells resulting in a rise in the relative proportion of cancer stem cell-like cells. However, carbon ion irradiation may eliminate both non-stem-like and stem-like tumor cells simultaneously, with minimal changes in the percentage of cancer stem cell-like cells in the population. The surviving fractions for the cancer stemlike cells after irradiation with X-rays or carbon ion beams declined exponentially with increasing doses, and the RBE values of carbon ion calculated at the D10 level for cancer stem-like cells isolated from MIA $\mathrm{PaCa}-2$ and $\mathrm{BxPc}-3$ were 2.0-2.19; this indicates that the carbon ion irradiation may be highly useful to eliminate cancer stem-like cells. On the contrary, RBE value at the D10 level for non-cancer stem-like cells sorted from MIA PaCa-2 was only 1.47, indicating that the difference in killing pancreatic cancer cells between carbon ion beam and X-rays might essentially result from the powerful effects of carbon ion irradiation on cancer stem-like cells [32]. In summary, these findings demonstrate the potential benefits of utilizing carbon ion irradiation for targeting pancreatic cancer stem-like cells which are resistant to conventional radiotherapy.

\section{Discussion}

The results of recent research indicate that tumors exhibit a cellular hierarchy, with a subpopulation of cancer cells possessing a tumorigenic potential much greater than that of other cancer cells. This extremely tumorigenic subpopulation of cells at the top of the hierarchy consists of cancer stem cells (CSCs) and generates progenitors and cells at different levels of differentiation along a variety of lineages [5].

CSCs possess the ability to self-renew and differentiate into various tumor components through stemness pathways, such as Wnt, TGF- $\beta$, STAT, and Hippo-YAP/TAZ. Stemness pathways in normal stem cells (NSCs) are stringently regulated and modulate many important biologic processes. On the contrary, stemness pathways in CSCs are highly dysregulated [1]. CSCs depend on distinct reprogrammed pathways to retain stemness and to play a part in the progression of cancers. The exact targeting of CSCs, along with chemotherapy or radiotherapy, may achieve steady remission or be an aid in curing cancer [2].

The study of Chen and colleagues demonstrated that melatonin precisely targeted glioma tumor cells by modifying glioblastoma stem-like cell (GSCs) biology and inhibiting GSC proliferation. AKTSTAT3-EZH2 signaling and EZH2 phosphorylation play essential roles in GSC growth. Melatonin attenuated AKT activation, EZH2 S21 phosphorylation, EZH2-STAT3 interactions and altered histone modifications to reduce tumor initiation and propagation. These results show that melatonin reduces multiple crucial signals associated with GSC self-renewal and survival [17]. 
Drug efflux by ATP-Binding Cassette (ABC) transporters is one of the mechanisms of CSC therapy resistance [169]. ABC-transporters are renowned for their involvement in multiple drug resistance in various human cancers [170]. Three proteins of the ABC transporter family were comprehensively examined as regulators of the multidrug resistance in tumors, including P-glycoprotein (P-gp, MDR1, ABCB1), multidrug resistance protein 1 (MRP1, $A B C C 1)$ and breast cancer resistance protein (BCRP, ABCG2) [171,172]. These three transporters have an extensive overlap in drug specificity offering tumor resistance to the principal classes of chemotherapeutic drugs and molecularly targeted therapies [32,33,173]. Inhibition of ABCG2 transporter activity with phosphodiesterase- 5 inhibitors and fumitremorgin-type indolyldiketopiperazine, Ko143, might intensify the efficacy of the chemotherapeutic agents $[174,175]$. In addition, Martin and colleagues documented that melatonin increases the efficacy of chemotherapeutic agents, targeting both the tumor bulk and brain tumor stem cells (BTSCs) through the regulation of the expression and function of the ABCG2/BCRP transporter by inducing the methylation of its promoter [18]. This result implies a probable correlation between the downregulation of ABCG2/BCRP function and the synergistic toxic effect of melatonin and chemotherapeutic agents [18]. Based on this, melatonin is a likely candidate to counteract multidrug resistance in the treatment of glioblastomas.

OCT4, a member of POU family, is a transcription factor that is required for self-renewal and maintenance of pluripotency of cancer stem cells $[60,176]$. Mammospheres treated with E2 or BPA markedly increased the binding of ER to the putative ERE (estrogen response elements) sequences in OCT4 transcription site OCT4-3544. Conversely, mammospheres exposed to E2 or BPA and treated with melatonin revealed a significant reduction in the binding of ER to the putative ERE sequences in OCT4 transcription site OCT4-3544. Additionally, mammospheres exposed to E2 or BPA slightly enhanced the binding of ER to ERE sites at $-1999 \mathrm{~kb}$ of OCT4 promoter region. This enhancement was reduced when mammospheres were treated with melatonin [20].

Autophagy captures, degrades, and recycles intracellular proteins and organelles in lysosomes. In most situations autophagy promotes tumorigenesis [177]. Cancers are able to upregulate autophagy to survive microenvironmental stress and to enhance growth and aggressiveness. Attempts to suppress autophagy to improve cancer therapy have attracted great attention [177]. The study of Martin and colleagues indicated that melatonin inhibited BTSCs proliferation and induced a reduction in self-renewal and clonogenic capability coexisted with a reduction in the expression of stem cell markers. In addition, the study also indicated that melatonin treatment induced cell death with ultrastructural characteristics of autophagy [21].

Recent studies have pointed out a connection between epithelial-tomesenchymal transition (EMT) and cancer stem cell (CSC) formation. EMT is involved in the acquisition and maintenance of stem cell-like characteristics and is adequate to endow differentiated normal and cancer cells with stem cell properties. In addition, CSCs usually exhibit EMT properties. This mutual relationship between EMT and CSCs might be related to tumor progression [178]. The study of Goncalves and colleagues demonstrated that melatonin exhibited an inhibitory role in the viability and invasiveness of breast cancer mammospheres as well as in inhibiting the expression of OCT4, N-cadherin and vimentin proteins associated with EMT in breast CSCs [19].

Intratumoral hypoxia, resistance to radiation-induced apoptosis, a high capacity for the repair of DNA double-strand breaks (DSBs), and mutations in certain oncogene and tumor suppressor genes are related to tumor resistance to X-ray radiotherapy [179]. Intratumoral hypoxia is a principal contributor to the X-ray resistance of cancer cells. Low pretreatment intratumoral $\mathrm{pO}_{2}$ values is related to poor outcomes after $\mathrm{X}$-ray radiotherapy. On the contrary, carbon ion radiotherapy revealed favorable antitumor effects in patients with locally advanced uterine cervical cancer, regardless of pretreatment intratumoral $\mathrm{pO}_{2}$ levels. Cancer cell resistance to radiation-induced apoptosis is another crucial factor that plays a part in X-ray resistance. Carbon ions effectively eliminate cancer cells that are resistant to apoptosis induced by X-ray irradiation. The high capacity of cancer cells for double-strand break (DSB) repair gives rise to X-ray resistance. Carbon ion-induced complex DSBs are more arduous to repair than X-ray-induced DSBs; these sustained unrepaired DSBs then result in mitotic catastrophe [179].

Glioma stem cells (GSCs) are related to tumorigenesis, recurrence and treatment resistance. CD133-positive glioma cells indicate the subpopulation that presents glioma radioresistance and is regarded as the source of tumor recurrence after radiotherapy. Huynh and colleagues demonstrated that GRP78, an antistress protein, was highly expressed in GBM cells associated with the development of GSCs. When GRP78 was silenced, GSC properties were inhibited and radiosensitivity increased [180]. Four photon radioresistant GSCs and U87MG GBM cells were irradiated with 4-Gy photon, proton, or carbon (28). Cell survival data demonstrated that NCH644 and NCH421k were the two most photon-resistant GSCs. Carbon ion irradiation at an isodose of 4 Gy revealed noticeable cell killing. Carbon ion irradiation is effective in GSC eradication [28].

There is a considerable amount of evidence that crosstalk between cancer cells and cells of neoplastic stroma is essential in the acquired capability for invasion and metastasis [181]. Migration and invasion were substantially increased by a 2 Gy photon irradiation in head and neck squamous cell carcinoma cells (SQ20B cells) [29]. Migration of SQ20B/ CSCs was profoundly reduced by carbon ion radiation. Carbon ion irradiation may be a prospective treatment option because it counteracts migration and invasion processes in both head and neck squamous cell carcinoma cells and CSCs in contrast to photon irradiation [29].

The relationship between XRCC4 and radiosensitivity of human colon cancer stem-like cell to X-ray or carbon ion beam was investigated by Sai and colleagues. XRCC4, a member of NHEJ (non-homologous end-joining) for double strand breaks, may play an essential role in carcinogenesis. XRCC4 inactivation notably radiosensitized human colon cancer stem-like cells. The expression of cancer stem-like cell markers were significantly enhanced by X-ray in contrast to carbon ion irradiation [182]. Carbon ion irradiation may simultaneously eliminate both non-stem-like and stem-like tumor cells; accordingly, the proportion of cancer stem-like cells slightly increases or remains stationary. Fifteen Gy carbon ion irradiation induced a more noticeable xenograft tumor cell cavitation and fibrosis without obvious enhancement of cells with putative cancer stem cell markers compared with that induced by $30 \mathrm{~Gy} \mathrm{X}$-ray irradiation. Carbon ion irradiation is a promising therapeutic modality owing to improved targeting of putative colon cancer stem-like cells.

Most patients diagnosed with pancreatic cancer do not attain factual responses owing to the existence of intrinsic and acquired radioresistance. Distinguishing of molecular mechanisms that diminish the efficacy of radiation therapy and targeting these pathways is important for improving radiation response in patients with pancreatic cancer [183]. In the study of Oonishi and colleagues, the proportion of 
cancer stem-like CD44+/CD24+ cells was more enriched after X-ray irradiation compared to carbon ion irradiation. The percentages of cancer stem cell-like CD44+/CD24+ cells increased remarkably by 3 - to 6 -fold after X-ray irradiation, whereas the proportion of these cells only doubled or decreased in pancreatic cancer stem-like cells after carbon ion irradiation [32]. The RBE values of carbon ion for pancreatic cancer stem-like cells ranged from 2.0 to 2.19 , indicating that the carbon ion beam has significant capability to eliminate pancreatic cancer stem-like cells.

\section{Conclusion}

Cancer stem cells exhibit an excessive migratory and invasive potential. These cells possess the capacity of self-renewal and pluripotency, generating all cells within a tumor, and are responsible for tumor growth, therapy resistance and metastasis.

Melatonin attenuated AKT activation, EZH2 S21 phosphorylation, EZH2-STAT3 interactions and altered histone modifications to reduce tumor initiation and propagation of brain tumor stem cells (BTSC). Melatonin reduces multiple crucial signals associated with BTSC self-renewal and survival. Melatonin increases the efficacy of chemotherapeutic agents, targeting both the tumor bulk and BTSCs through the regulation of the expression and function of the ABCG2/ BCRP transporter by inducing the methylation of its promoter. There is also a possible correlation between the downregulation of ABCG2/BCRP function and the synergistic toxic effect of melatonin and chemotherapeutic agents. Melatonin may be a worthy candidate to counteract multidrug resistance in the treatment of glioblastomas. Melatonin treatment induced cell death with ultrastructural characteristics of autophagy.

Melatonin inhibited the effects of E2 and BPA treatment on mammosphere growth together with the expression of ERa and the stem cell marker OCT4. Melatonin treatment is effective in inhibiting the proliferation of breast cancer stem cells (BCSCs) and influences the ER pathway. The BCSCs are responsive to melatonin treatment by way of reducing the viability and the invasiveness of breast cancer mammospheres as well as regulating the expression of OCT4, $\mathrm{N}$-cadherin and vimentin proteins associated with EMT in BCSCs.

As compared with photon irradiation, a higher percentage (2.4fold) of brain tumor stem cells (BTSCs) stained positive for nuclear $\gamma$-H2AX 24 hours after carbon ion irradiation, documenting residual unrepaired double-strand breaks. Sensitivity of cancer stem cells to carbon ions might be a result of the impaired capability of BTSCs to repair carbon ion-induced DNA double-strand breaks. Carbon irradiation is effective in BTSCs elimination with RBE in the range of 1.87-3.44.

A subpopulation of head and neck cancer stem cells characterized by high migratory and invasive capacities, a low EGFR expression and a resistance to cetuximab, which may promote local recurrence and distant metastasis in HNSCC after treatment. Carbon ion irradiation seems to be a promising therapeutic modality because it resists migration and invasion processes in both head and neck squamous cell carcinoma cells and cancer stem cells in contrast to photon irradiation.

Principal effects of carbon ion beam in combination with CDDP on TNBC cell killing primarily result from effective elimination of radioresistant TNBCSCs. Carbon ion irradiation combined with CDDP provides significant advantages for targeting TNBCSCs as a result of complex DNA damage, increased apoptosis, autophagy, and subsequent cell death compared to conventional X-ray or carbon ion irradiation alone.
In vivo FACS analyses revealed that the percentage of CD133+/ ESA+ colon cancer stem-like cells increased 1 month after 15 and $30 \mathrm{~Gy} \mathrm{X}$-ray irradiation. In contrast, $30 \mathrm{~Gy}$ of carbon ion irradiation significantly reduced the percentage of colon cancer stem-like cells. Low LET X-ray irradiation may essentially eradicate the non-stemlike tumor cell, consequently the radioresistant cancer stem-like cell population is obviously enriched. In contrast, carbon ion irradiation may simultaneously eradicate both non-stem-like and stem-like tumor cells at the same time. Carbon ion irradiation is clearly a promising agent to eradicate putative colon cancer stem-like cells.

The number of tumor spheroid formations is significantly lower in carbon ion irradiated cancer stem-like cells sorted from human pancreatic cancer cell lines, MIA PaCa-2 and BxPc-3 cells, compared to that of X-ray irradiated ones. The surviving fractions for the cancer stem-like cells after irradiation with X-rays or carbon ions declined exponentially with increasing doses, and the RBE values of carbon ion for cancer stem-like cells isolated from MIA PaCa-2 and BxPc-3 were about 2.0-2.19, indicating that the carbon ion beam has significant potential to eliminate pancreatic cancer stem-like cells.

Further investigation to elucidate the mechanisms and molecular pathways involved in cancer stem cells particularly associated with melatonin and carbon ion irradiation certainly is warranted. Finally, considering the similar actions of melatonin and carbon ion irradiation in terms of altering the features of cancer stem cells in tumors, a combination therapy using these two agents may be highly worthwhile.

\section{References}

1. Ajani JA, Song S, Hochster HS, Steinberg IB (2015) Cancer stem cells: the promise and the potential. Semin Oncol. 42 Suppl 1: S3-17.

2. Qiu H, Fang X, Luo Q, Ouyang G (2015) Cancer stem cells: a potential target for cancer therapy. Cell Mol Life Sci 72: 3411-3424. [Crossref]

3. Luo M, Clouthier SG, Deol Y, Liu S, Nagrath S, et al. (2015) Breast cancer stem cells current advances and clinical implications. Methods Mol Biol 1293: 1-49. [Crossref]

4. Sehl ME, Shimada M, Landeros A, Lange K, Wicha MS (2015) Modeling of Cancer Stem Cell State Transitions Predicts Therapeutic Response. PLoS One 10: e0135797. [Crossref]

5. Yoshida GJ, Saya H (2016) Therapeutic strategies targeting cancer stem cells. Cancer Sci 107: 5-11. [Crossref]

6. Zhao Y, Alakhova DY, Kabanov AV (2013) Can nanomedicines kill cancer stem cells? Adv Drug Deliv Rev 65: 1763-1783. [Crossref]

7. Vijayalaxmi, Thomas CR Jr, Reiter RJ, Herman TS (2002) Melatonin: from basic research to cancer treatment clinics. J Clin Oncol 20: 2575-2601.

8. Cabrera J, Negrín G, Estévez F, Loro J, Reiter RJ, et al. (2010) Melatonin decreases cell proliferation and induces melanogenesis in human melanoma SK-MEL-1 cells. $J$ Pineal Res 49: 45-54.

9. Carbajo-Pescador S, García-Palomo A, Martín-Renedo J, Piva M, GonzálezGallego J, et al. (2011) Melatonin modulation of intracellular signaling pathways in hepatocarcinoma HepG2 cell line: role of the MT1 receptor. J Pineal Res 51: 463-471.

10. Sanchez-Barcelo EJ, Mediavilla MD, Alonso-Gonzalez C, Reiter RJ (2012) Melatonin uses in oncology: breast cancer prevention and reduction of the side effects of chemotherapy and radiation. Expert Opin Investig Drugs 21: 819-831.

11. Cutando A, López-Valverde A, Arias-Santiago S, Vicente J, Diego RG (2012) Role of melatonin in cancer treatment. Anticancer Res 32: 2747-2753. [Crossref]

12. Carbajo-Pescador S, Ordonez R, Benet M, Jover R, Garcia-Palomo A, et al. (2013) Inhibition of VEGF expression through blockade of Hifla and STAT3 signalling mediates the anti-angiogenic effect of melatonin in HepG2 liver cancer cells. $\mathrm{Br} \mathrm{J}$ Cancer 109: 83-91.

13. Reiter RJ, Tan DX, Galano A (2014) Melatonin: exceeding expectations. Physiology (Bethesda) 29: 325-333. [Crossref]

14. Pariente R, Pariente JA, Rodríguez AB, Espino J (2016) Melatonin sensitizes human cervical cancer HeLa cells to cisplatin-induced cytotoxicity and apoptosis: effects on oxidative stress and DNA fragmentation. $J$ Pineal Res 60: 55-64. 
15. Wei JY, Li WM, Zhou LL, Lu QN, He W (2015) Melatonin induces apoptosis of colorectal cancer cells through HDAC4 nuclear import mediated by CaMKII inactivation. J Pineal Res 58: 429-438.

16. Bizzarri M, Proietti S, Cucina A, Reiter RJ (2013) Molecular mechanisms of the proapoptotic actions of melatonin in cancer: a review. Expert Opin Ther Targets 17: 14831496. [Crossref]

17. Chen X, Hao A, Li X, Du Z, et al. (2016) Melatonin inhibits tumorigenicity of glioblastoma stem-like cells via the AKT-EZH2-STAT3 signaling axis. J Pineal Res 61: 208-217. [Crossref]

18. Martin V, Sanchez-Sanchez AM, Herrera F, Gomez-Manzano C, Fueyo J, et al. (2013) Melatonin-induced methylation of the ABCG2/BCRP promoter as a novel mechanism to overcome multidrug resistance in brain tumour stem cells. Br J Cancer 108: 20052012.

19. Gonçalves Ndo N, Colombo J, Lopes JR, Gelaleti GB, Moschetta MG, et al. (2016) Effect of melatonin in epithelial mesenchymal transition markers and invasive properties of breast cancer stem cells of canine and human cell lines. PLoS One 11: e0150407.

20. Lopes J, Arnosti D, Trosko JE, Tai MH, Zuccari D. (2016) Melatonin decreases estrogen receptor binding to estrogen response elements sites on the OCT4 gene in human breast cancer stem cells. Genes Cancer 7: 209-217.

21. Martin V, Sanchez-Sanchez AM, Puente-Moncada N, Gomez-Lobo M, Alvarez-Vega MA, et al. (2014) Involvement of autophagy in melatonin-induced cytotoxicity in glioma-initiating cells. J Pineal Res 57: 308-316.

22. Baskar R, Lee KA, Yeo R, Yeoh KW (2012) Cancer and radiation therapy: curren advances and future directions. Int J Med Sci 9: 193-199. [Crossref]

23. Su WH, Chuang PC, Huang EY, Yang KD (2012) Radiation-induced increase in cell migration and metastatic potential of cervical cancer cells operates via the K-Ras pathway. Am J Pathol 180: 862-871.

24. Bert C, Engenhart-Cabillic R, Durante M (2012) Particle therapy for noncancer diseases. Med Phys 39: 1716-1727. ?

25. Tsujii H, Kamada T (2012) A review of update clinical results of carbon ion radiotherapy. Jpn J Clin Oncol 42: 670-685.

26. Helm A, Lee R, Durante M, Ritter S (2016) The Influence of C-Ions and X-rays on Human Umbilical Vein Endothelial Cells. Front Oncol 6: 5. [Crossref]

27. Hamada N, Imaoka T, Masunaga S, Ogata T, Okayasu R, et al. (2010) Recent advances in the biology of heavy-ion cancer therapy. J Radiat Res 51: 365-383. [Crossref]

28. Chiblak S, Tang Z, Campos B, Gal Z, Unterberg A, et al. (2016) Radiosensitivity of patient-derived glioma stem cell 3-dimensional cultures to photon, proton, and carbon irradiation. Int J Radiat Oncol Biol Phys 95: 112-119.

29. Moncharmont C, Guy JB, Wozny AS, Gilormini M, Battiston-Montagne P, et al. (2016) Carbon ion irradiation withstands cancer stem cells' migration/invasion process in Head and Neck Squamous Cell Carcinoma (HNSCC). Oncotarget 7: 47738-47749.

30. Sai S, Vares G, Kim EH, Karasawa K, Wang B, et al. (2015) Carbon ion beam combined with cisplatin effectively disrupts triple negative breast cancer stem-like cells in vitro. Mol Cancer 14:166.

31. Cui X, Oonishi K, Tsujii H, Yasuda T, Matsumoto Y, et al. (2011) Effects of carbon ion beam on putative colon cancer stem cells and its comparison with X-rays. Cancer Res 71: 3676-3687. [Crossref]

32. Oonishi K, Cui X, Hirakawa H, Fujimori A, Kamijo T, et al. (2012) Different effects of carbon ion beams and X-rays on clonogenic survival and DNA repair in human pancreatic cancer stem-like cells. Radiother Oncol 105: 258-265.

33. Bao S, Wu Q, McLendon RE, Hao Y, Shi Q, et al. (2006) Glioma stem cells promote radioresistance by preferential activation of the DNA damage response. Nature 444:756-760.

34. Chen J, Li Y, Yu TS, McKay RM, Burns DK, et al. (2012) A restricted cell population propagates glioblastoma growth after chemotherapy. Nature 488: 522-526.

35. Auffinger B, Tobias AL, Han Y, Lee G, Guo D, et al. (2014) Conversion of differentiated cancer cells into cancer stem-like cells in a glioblastoma model after primary chemotherapy. Cell Death Differ 21: 1119-1131.

36. Richly H, Aloia L, Di Croce L (2011) Roles of the Polycomb group proteins in stem cells and cancer. Cell Death Dis 2: e204. [Crossref]

37. Vaswani RG, Gehling VS, Dakin LA, Cook AS, Nasveschuk CG, et al. (2016) Identification of (R)-N-((4-Methoxy-6-methyl-2-oxo-,2-dihydropyridin-3-yl)methyl)2-methyl-1-(1-(1-(2,2,2-trifluoroethyl)piperidin-4-yl)ethyl)-1H-indole-3-carboxamide (CPI-1205), a Potent and Selective Inhibitor of Histone Methyltransferase EZH2, Suitable for Phase I Clinical Trials for B-Cell Lymphomas. J Med Chem 59: 9928-9941.
38. McCabe MT, Ott HM, Ganji G, Korenchuk S, Thompson C, et al. (2012) EZH2 inhibition as a therapeutic strategy for lymphoma with EZH2-activating mutations. Nature 492: 108-112. [Crossref]

39. Kondo Y (2014) Targeting histone methyltransferase EZH2 as cancer treatment. $J$ Biochem 156: 249-257. [Crossref]

40. Comet I, Riising EM, Leblanc B, Helin K, et al. (2016) Maintaining cell identity: PRC2-mediated regulation of transcription and cancer. Nat Rev Cancer 16: 803-810. [Crossref]

41. Fresno Vara JA, Casado E, de Castro J, Cejas P, Belda-Iniesta C, et al. (2004) PI3K/Akt signalling pathway and cancer. Cancer Treat Rev 30: 193-204. [Crossref]

42. Chen J, Somanath PR, Razorenova O, Chen WS, Hay N, et al. (2005) Akt1 regulates pathological angiogenesis, vascular maturation and permeability in vivo. Nat Med 11 1188-1196.

43. Somanath PR, Razorenova OV, Chen J, Byzova TV (2006) Akt1 in endothelial cell and angiogenesis. Cell Cycle 5: 512-518. [Crossref]

44. Fan QW, Weiss WA (2010) Targeting the RTK-PI3K-mTOR axis in malignant glioma overcoming resistance. Curr Top Microbiol Immunol 347: 279-296. [Crossref]

45. Li X, Wu C, Chen N, Gu H, Yen A, et al. (2016) PI3K/Akt/mTOR signaling pathway and targeted therapy for glioblastoma. Oncotarget 7: 33440-33450.

46. Birner P, Pusch S, Christov C, Mihaylova S, Toumangelova-Uzeir K, et al. (2014) Mutant IDH1 inhibits PI3K/Akt signaling in human glioma. Cancer 120: 2440-2447. [Crossref]

47. McDowell KA, Riggins GJ, Gallia GL (2011) Targeting the AKT pathway in glioblastoma. Curr Pharm Des 17: 2411-2420.

48. Höland K, Salm F, Arcaro A (2011) The phosphoinositide 3-kinase signaling pathway as a therapeutic target in grade IV brain tumors. Curr Cancer Drug Targets 11: 894918. [Crossref]

49. Kim E, Kim M, Woo DH, Shin Y, Shin J, et al. (2013) Phosphorylation of EZH2 activates STAT3 signaling via STAT3 methylation and promotes tumorigenicity of glioblastoma stem-like cells. Cancer Cell 23: 839-852. [Crossref]

50. Dasgupta M, Dermawan JK, Willard B, Stark GR (2015) STAT3-driven transcription depends upon the dimethylation of K49 by EZH2. Proc Natl Acad Sci USA 112: 3985 3990. [Crossref]

51. Kogure M, Takawa M, Saloura V, Sone K, Piao L, et al. (2013) The oncogenic polycomb histone methyltransferase EZH2 methylates lysine 120 on histone $\mathrm{H} 2 \mathrm{~B}$ and competes ubiquitination. Neoplasia 15: 1251-1261.

52. Chen B, Liu J, Chang Q, Beezhold K, Lu Y, et al. (2013) JNK and STAT3 signaling pathways converge on Akt- mediated phosphorylation of EZH2 in bronchial epithelial cells induced by arsenic. Cell Cycle 12:112-121.

53. Rojanasakul Y (2013) Linking JNK-STAT3-Akt signaling axis to EZH2 phosphorylation: a novel pathway of carcinogenesis. Cell Cycle 12: 202-203. [Crossref]

54. Galli R, Binda E, Orfanelli U, Cipelletti B, Gritti A, et al. (2004) Isolation and characterization of tumorigenic, stem-like neural precursors from human glioblastoma. Cancer Res 64: 7011-7021. [Crossref]

55. Günther HS, Schmidt NO, Phillips HS, Kemming D, Kharbanda S, et al. (2008) Glioblastoma-derived stem cell-enriched cultures form distinct subgroups according to molecular and phenotypic criteria. Oncogene 27: 2897-2909.

56. Piccirillo SG, Combi R, Cajola L, Patrizi A, Redaelli S, et al. (2009) Distinct pools of cancer stem-like cells coexist within human glioblastomas and display different tumorigenicity and independent genomic evolution. Oncogene 28: 1807-1811.

57. Balbous A, Cortes U, Guilloteau K, et al. (2016) A radiosensitizing effect of RAD51 inhibition in glioblastoma stem-like cells. BMC Cancer 16: 604. [Crossref]

58. Kenific CM, Debnath J (2015) Cellular and metabolic functions for autophagy in cancer cells. Trends Cell Biol 25: 37-45. [Crossref]

59. Kaur J, Debnath J (2015) Autophagy at the crossroads of catabolism and anabolism. Nat Rev Mol Cell Biol 16: 461-472. [Crossref]

60. Wang YJ, Herlyn M (2015) The emerging roles of Oct4 in tumor-initiating cells. Am J Physiol Cell Physiol 309: C709-718. [Crossref]

61. Seymour T, Nowak A, Kakulas F (2015) Targeting Aggressive Cancer Stem Cells in Glioblastoma. Front Oncol 5: 159. [Crossref]

62. Curry EL, Moad M, Robson CN, Heer R (2015) Using induced pluripotent stem cells as a tool for modelling carcinogenesis. World J Stem Cells 7: 461-469. [Crossref] 
63. Jung JW, Park SB, Lee SJ, Seo MS, Trosko JE, et al. (2011) Metformin represses selfrenewal of the human breast carcinoma stem cells via inhibition of estrogen receptormediated OCT4 expression. PLoS One 6: e28068.

64. Vazquez Rodriguez G, Abrahamsson A, Jensen LD2, Dabrosin C3 (2017) Estradiol Promotes Breast Cancer Cell Migration via Recruitment and Activation of Neutrophils. Cancer Immunol Res 5: 234-247. [Crossref]

65. Pupo M, Pisano A, Lappano R, Santolla MF, De Francesco EM, et al. (2012) Bisphenol A induces gene expression changes and proliferative effects through GPER in breast cancer cells and cancer-associated fibroblasts. Environ Health Perspect 120: 1177-1182.

66. Song H, Zhang T, Yang P, Li M, Yang Y, et al. (2015) Low doses of bisphenol A stimulate the proliferation of breast cancer cells via ERK1/2/ERR $\hat{I}^{3}$ signals. Toxicol In Vitro 30: 521-528. [Crossref]

67. Usui T, Sakurai M, Enjoji S, Kawasaki H, Umata K, et al. (2016) Establishment of a Novel Model for Anticancer Drug Resistance in Three-Dimensional Primary Culture of Tumor Microenvironment. Stem Cells Int 2016: 7053872.

68. Hubert CG, Rivera M, Spangler LC, Wu Q, Mack SC, et al. (2016) A Three-Dimensional Organoid Culture System Derived from Human Glioblastomas Recapitulates the Hypoxic Gradients and Cancer Stem Cell Heterogeneity of Tumors Found In Vivo. Cancer Res 76: 2465-2477.

69. Han XY, Wei B, Fang JF, Zhang S, Zhang FC, et al. (2013) Epithelial-mesenchymal transition associates with maintenance of stemness in spheroid-derived stem-like colon cancer cells. PLoS One 8: e73341.

70. Xu MH, Gao X, Luo D, Zhou XD, Xiong W, et al. (2014) EMT and acquisition of stem cell-like properties are involved in spontaneous formation of tumorigenic hybrids between lung cancer and bone marrow-derived mesenchymal stem cells. PLoS One 9: e87893.

71. Grosse-Wilde A, Fouquier d'Hérouël A2, McIntosh E, Ertaylan G3, Skupin A2, et al. (2015) Stemness of the hybrid Epithelial/Mesenchymal State in Breast Cancer and Its Association with Poor Survival. PLoS One 10: e126522. [Crossref]

72. Hollestelle A, Peeters JK, Smid M, Timmermans M, Verhoog LC, et al. (2013) Loss of E-cadherin is not a necessity for epithelial to mesenchymal transition in human breas cancer. Breast Cancer Res Treat 138: 47-57. [Crossref]

73. Zhang Z, Yang C, Gao W, Chen T, Qian T, et al. (2015) FOXA2 attenuates the epithelial to mesenchymal transition by regulating the transcription of E-cadherin and ZEB2 in human breast cancer. Cancer Lett 361: 240-250. [Crossref]

74. Lin YC, Lee YC, Li LH, Cheng CJ, Yang RB (2014) Tumor suppressor SCUBE2 inhibits breast-cancer cell migration and invasion through the reversal of epithelialmesenchymal transition. J Cell Sci 127: 85-100.

75. Manuel Iglesias J, Beloqui I, Garcia-Garcia F, Leis O, Vazquez-Martin A, et al. (2013) Mammosphere formation in breast carcinoma cell lines depends upon expression of E-cadherin. PLoS One 8: e77281.

76. Klopp AH, Lacerda L, Gupta A, Debeb BG, Solley T, et al. (2010) Mesenchymal stem cells promote mammosphere formation and decrease E-cadherin in normal and malignant breast cells. PLoS One 5: e12180. [Crossref]

77. Lacerda L, Debeb BG, Smith D, Larson R, Solley T, et al. (2015) Mesenchymal stem cells mediate the clinical phenotype of inflammatory breast cancer in a preclinical model. Breast Cancer Res 17: 42-58.

78. Kalluri R, Weinberg RA (2009) The basics of epithelial-mesenchymal transition. J Clin Invest 119: 1420-1428. [Crossref]

79. Luft FC (2015) Targeting epithelial-mesenchymal transition. J Mol Med (Berl) 93: 703705. [Crossref]

80. Zhao H, Wu QQ, Cao LF, Qing HY, Zhang C, et al. (2014) Melatonin inhibits endoplasmic reticulum stress and epithelial-mesenchymal transition during bleomycininduced pulmonary fibrosis in mice. PLoS One 9: e97266.

81. Hill SM, Belancio VP, Dauchy RT, Xiang S, Brimer S, et al. (2015) Melatonin: an inhibitor of breast cancer. Endocr Relat Cancer 22: R183-204. [Crossref]

82. Mao L, Summers W, Xiang S, et al. (2016) Melatonin Represses Metastasis in Her2Postive Human Breast Cancer Cells by Suppressing RSK2 Expression. Mol Cancer Res 14: 1159-1169. [Crossref]

83. Ferletta M, Grawé J, Hellmén E (2011) Canine mammary tumors contain cancer stemlike cells and form spheroids with an embryonic stem cell signature. Int J Dev Biol 55: 791-799. [Crossref]

84. Torres CG, Olivares A, Stoore C (2015) Simvastatin exhibits antiproliferative effects on spheres derived from canine mammary carcinoma cells. Oncol Rep 33: 2235-2244.
85. Barbieri F, Thellung S, Ratto A, Carra E, Marini V, et al. (2015) In vitro and in vivo antiproliferative activity of metformin on stem-like cells isolated from spontaneous canine mammary carcinomas: translational implications for human tumors. BMC Cancer 15: 228.

86. Karamboulas C, Ailles L (2013) Developmental signaling pathways in cancer stem cells of solid tumors. Biochim Biophys Acta 1830: 2481-2495. [Crossref]

87. Owens TW, Naylor MJ (2013) Breast cancer stem cells. Front Physiol 4: 225. [Crossref]

88. Dittmer J, Rody A (2013) Cancer stem cells in breast cancer. Histol Histopathol 28: 827-838. [Crossref]

89. Dandawate PR, Subramaniam D, Jensen RA, Anant S (2016) Targeting cancer stem cells and signaling pathways by phytochemicals: Novel approach for breast cancer therapy. Semin Cancer Biol 40-41: 192-208.

90. Dontu G, Abdallah WM, Foley JM, Jackson KW, Clarke MF, et al. (2003) In vitro propagation and transcriptional profiling of human mammary stem/progenitor cells Genes Dev 17:1253-1270.

91. Ponti D, Costa A, Zaffaroni N, Pratesi G, Petrangolini G, et al. (2005) Isolation and in vitro propagation of tumorigenic breast cancer cells with stem/progenitor cell properties. Cancer Res 65: 5506-5511. [Crossref]

92. Linn DE, Yang X, Sun F, Xie Y, Chen H, et al. (2010) A Role for OCT4 in Tumor Initiation of Drug-Resistant Prostate Cancer Cells. Genes Cancer 1: 908-916. [Crossref]

93. Chang CJ, Chien Y, Lu KH, Chang SC, Chou YC, et al. (2011) Oct4-related cytokine effects regulate tumorigenic properties of colorectal cancer cells. Biochem Biophys Res Commun 415: 245-251.

94. Saigusa S, Tanaka K, Toiyama Y, Yokoe T, Okugawa Y, et al. (2009) Correlation of CD133, OCT4, and SOX2 in rectal cancer and their association with distant recurrence after chemoradiotherapy. Ann Surg Oncol 16: 3488-3498.

95. Lemos C, Hardt MS, Juneja M, Voss C, Förster S, et al. (2016) MACC1 induces tumor progression in transgenic mice and colorectal cancer patients via increased pluripotency markers Nanog and Oct4. Clin Cancer Res 22: 2812-2824.

96. Chiou SH, Wang ML, Chou YT, Chen CJ, Hong CF, et al. (2010) Coexpression of Oct4 and Nanog enhances malignancy in lung adenocarcinoma by inducing cancer stem cell-like properties and epithelial-mesenchymal transdifferentiation. Cancer Res 70: 10433-10444.

97. Li B, Yao Z, Wan Y, Lin D1 (2016) Overexpression of OCT4 is associated with gefitinib resistance in non-small cell lung cancer. Oncotarget 7: 77342-77347. [Crossref]

98. Guo Y, Liu S, Wang P, Zhao S, Wang F, et al. (2011) Expression profile of embryonic stem cell-associated genes Oct4, Sox2 and Nanog in human gliomas. Histopathology 59: 763-775. [Crossref]

99. Safa AR, Saadatzadeh MR, Cohen-Gadol AA, Pollok KE, Bijangi-Vishehsaraei K (2016) Emerging targets for glioblastoma stem cell therapy. J Biomed Res 30: 19-31.

100. Puck TT, Marcus PI (1956) Action of x-rays on mammalian cells. J Exp Med 103: 653-666. [Crossref]

101. Puck TT, Morkovind D, Marcus PI, Cieciura SJ (1957) Action of x-rays on mammalian cells. II. Survival curves of cells from normal human tissues. $J$ Exp Med 106: 485-500. [Crossref]

102. Combs SE, Ellerbrock M, Haberer T, Habermehl D, Hoess A, et al. (2010) Heidelberg Ion Therapy Center (HIT): Initial clinical experience in the first 80 patients. Acta Oncol 49: 1132-1140.

103. Combs S, Jakel O, Haberer T, Debus J (2010): Particle therapy at the Heidelberg Ion Therapy Center (HIT) - Integrated research-driven university-hospital based radiation oncology service in Heidelberg, Germany. Radiother Oncol 95: 41-44.

104. Sharungbam GD, Schwager C, Chiblak S, Brons S, Hlatky L, et al. (2012) Identification of stable endogenous control genes for transcriptional profiling of photon, proton and carbon-ion irradiated cells. Radiat Oncol 7: 70.

105. Ropolo M, Daga A, Griffero F, Foresta M, Casartelli G, et al. (2009) Comparative analysis of DNA repair in stem and nonstem glioma cell cultures. Mol Cancer Res 7: 383-392. [Crossref]

106. Sai S, Wakai T, Vares G, Yamada S, Kamijo T, et al. (2015) Combination of carbon ion beam and gemcitabine causes irreparable DNA damage and death of radioresistant pancreatic cancer stem-like cells in vitro and in vivo. Oncotarget 6: 5517-5535.

107. Cooper JS, Porter K, Mallin K, Hoffman HT, Weber RS, et al. (2009) National Cancer Database report on cancer of the head and neck: 10-year update. Head Neck 31: 748758. [Crossref] 
108. Argiris A, Karamouzis MV, Raben D, Ferris RL (2008) Head and neck cancer. Lancet 371: 1695-1709. [Crossref]

109. Wan XC, Egloff AM, Johnson J (2012) Histological assessment of cervical lymph node identifies patients with head and neck squamous cell carcinoma (HNSCC): who would benefit from chemoradiation after surgery? Laryngoscope 122: 2712-2722.

110. Petrelli F, Coinu A, Riboldi V, Borgonovo K, Ghilardi M, et al. (2014) Concomitant platinum-based chemotherapy or cetuximab with radiotherapy for locally advanced head and neck cancer: a systematic review and meta-analysis of published studies. Oral Oncol 50: 1041-1048.

111. Chung CH, Rudek MA, Kang H, Marur S, John P, et al. (2016) A phase I study afatinib/carboplatin/paclitaxel induction chemotherapy followed by standard chemoradiation in HPV-negative or high-risk HPV-positive locally advanced stage $\mathrm{III} / \mathrm{IVa} / \mathrm{IVb}$ head and neck squamous cell carcinoma. Oral Oncol 53: 54-59.

112. Budach W, Bölke E, Kammers K, Gerber PA, Orth K, et al. (2016) Induction chemotherapy followed by concurrent radio-chemotherapy versus concurrent radiochemotherapy alone as treatment of locally advanced squamous cell carcinoma of the head and neck (HNSCC): A meta-analysis of randomized trials. Radiother Oncol 118: $238-243$.

113. Kamali A, Gahm C, Palmgren B, Marklund L, Halle M, et al. (2017) Regiona recurrence in early stage I-II oral tongue cancer: a single institutional study and review of the literature. Acta Otolaryngol 137: 755-761.

114. O'Sullivan B, Rumble RB, Warde P; Members of the IMRT Indications Expert Pane (2012) Intensity-modulated radiotherapy in the treatment of head and neck cancer. Clin Oncol (R Coll Radiol) 24: 474-487. [Crossref]

115. Choy C, Raytis JL, Smith DD, Duenas M, Neman J, et al. (2016) Inhibition of B2adrenergic receptor reduces triple-negative breast cancer brain metastases: The potential benefit of perioperative ß-blockade. Oncol Rep 35: 3135-3142.

116. Zhao J, Ou B, Han D, Wang P, Zong Y, et al. (2017) Tumor-derived CXCL5 promotes human colorectal cancer metastasis through activation of the ERK/Elk-1/Snail and AKT/GSK3ß/ß-catenin pathways. Mol Cancer 16: 70.

117. Schuettler D, Piontek G, Wirth M, Haller B, Reiter R, et al. (2015) Selective inhibition of EGFR downstream signaling reverses the irradiation-enhanced migration of HNSCC cells. Am J Cancer Res 5: 2660-2672.

118. Pickhard AC, Margraf J, Knopf A, Stark T, Piontek G, et al. (2011) Inhibition of radiation induced migration of human head and neck squamous cell carcinoma cells by blocking of EGF receptor pathways. BMC Cancer 11: 388 .

119. Lee SY, Jeong EK, Ju MK, Jeon HM, Kim MY, et al. (2017) Induction of metastasis, cancer stem cell phenotype, and oncogenic metabolism in cancer cells by ionizing radiation. Mol Cancer 16: 10-34.

120. Zhou YC, Liu JY, Li J, Zhang J, Xu YQ, et al. (2011) Ionizing radiation promotes migration and invasion of cancer cells through transforming growth factor-betamediated epithelial-mesenchymal transition. Int J Radiat Oncol Biol Phys 81: 1530-1537.

121. Park CM, Park MJ, Kwak HJ, Lee HC, Kim MS, et al. (2006) Ionizing radiation enhances matrix metalloproteinase-2 secretion and invasion of glioma cells through Src/epidermal growth factor receptor-mediated p38/Akt and phosphatidylinositol 3-kinase/Akt signaling pathways. Cancer Res 66: 8511-8519.

122. Dent P, Yacoub A, Contessa J, Caron R, Amorino G, et al. (2003) Stress and radiationinduced activation of multiple intracellular signaling pathways. Radiat Res 159: 283300 .

123. Cheng JC-H, Chou CH, Kuo ML, Hsieh C-Y (2006) Radiation- enhanced hepatocellular carcinoma cell invasion with MMP-9 expression through PI3K/Akt/ NF-kappaB signal transduction pathway. Oncogene 25: 7009-7018.

124. Park SK, Hwang YS, Park KK, Park HJ, Seo JY, et al. (2009) Kalopanaxsaponin A inhibits PMA-induced invasion by reducing matrix metalloproteinase-9 via PI3K/Akt- and PKCdelta-mediated signaling in MCF-7 human breast cancer cells. Carcinogenesis 30: 1225-1233.

125. Krause M, Yaromina A, Eicheler W, Koch U, Baumann M (2011) Cancer stem cells: targets and potential biomarkers for radiotherapy. Clin Cancer Res 17: 7224-7229. [Crossref]

126. Skvortsova I, Debbage P, Kumar V, Skvortsov S (2015) Radiation resistance: Cancer stem cells (CSCs) and their enigmatic pro-survival signaling. Semin Cancer Biol 35: $39-44$.

127. Han J, Fujisawa T, Husain SR, Puri RK (2014) Identification and characterization of cancer stem cells in human head and neck squamous cell carcinoma. BMC Cancer 14: 173. [Crossref]
128. Wang J, Wu Y, Gao W, Li F, Bo Y, et al. (2017) Identification and characterization of CD133+CD44+ cancer stem cells from human laryngeal squamous cell carcinoma cell lines. $J$ Cancer 8: 497-506. [Crossref]

129. Seino S, Shigeishi H, Hashikata M, Higashikawa K, Tobiume K, et al. (2016) CD44(high) /ALDH1(high) head and neck squamous cell carcinoma cells exhibit mesenchymal characteristics and GSK3ß-dependent cancer stem cell properties. $J$ Oral Pathol Med 45: 180-188. [Crossref]

130. Allegra E, Trapasso S (2012) Cancer stem cells in head and neck cancer. Onco Targets Ther 5: 375-383. [Crossref]

131. Bertrand G, Maalouf M, Boivin A, Battiston-Montagne P, Beuve M, et al. (2014) Targeting head and neck cancer stem cells to overcome resistance to photon and carbon ion radiation. Stem Cell Rev 10: 114-126. [Crossref]

132. Ghadjar P, Simcock M, Studer G, Allal AS, Ozsahin M, et al. (2012) Concomitan cisplatin and hyperfractionated radiotherapy in locally advanced head and neck cancer: 10-year follow-up of a randomized phase III trial (SAKK 10/94). Int J Radiat Oncol Biol Phys 82: 524-531.

133. Moreno-Jiménez M, Valero J, López-Picazo JM, Arbea L, Aristu J, et al. (2010) Concomitant cisplatin, paclitaxel, and hyperfractionated radiotherapy in locally advanced head and neck cancer: comparison of two different schedules. Am J Clin Oncol 33: 137-143.

134. Okano S, Yoshino T, Fujii M, Onozawa Y, Kodaira T, et al. (2013) Phase II study of cetuximab plus concomitant boost radiotherapy in Japanese patients with locally advanced squamous cell carcinoma of the head and neck. Jpn J Clin Oncol 43: 476-482.

135. Matuschek C, Bölke E, Belka C, Ganswindt U, Henke M, et al. (2013) Feasibility of 6-month maintenance cetuximab after adjuvant concurrent chemoradiation plus cetuximab in squamous cell carcinoma of the head and neck. Strahlenther Onkol 189: 625-631.

136. Pfister DG, Su YB, Kraus DH, Wolden SL, Lis E, et al. (2006) Concurrent cetuximab, cisplatin, and concomitant boost radiotherapy for locoregionally advanced, squamous cell head and neck cancer: a pilot phase II study of a new combined-modality paradigm. J Clin Oncol 24: 1072-1078.

137. Bonner JA, Harari PM, Giralt J, Cohen RB, Jones CU, et al. (2010) Radiotherapy plus cetuximab for locoregionally advanced head and neck cancer: 5-year survival data from a phase 3 randomised trial, and relation between cetuximab-induced rash and survival. Lancet Oncol 11:21-28.

138. Beuve M, Alphonse G, Maalouf M, Colliaux A, Battiston-Montagne P, et al. (2008) Radiobiologic parameters and local effect model predictions for head-and-neck squamous cell carcinomas exposed to high linear energy transfer ions. Int J Radiat Oncol Biol Phys 71: 635-642.

139. Mizoe JE, Hasegawa A, Jingu K, Takagi R, Bessyo H, et al. (2012) Results of carbon ion radiotherapy for head and neck cancer. Radiother Oncol 103: 32-37. [Crossref]

140. Koto M, Hasegawa A, Takagi R, Ikawa H, Naganawa K, et al. (2016) Evaluation of the safety and efficacy of carbon ion radiotherapy for locally advanced adenoid cystic carcinoma of the tongue base. Head Neck 38 Suppl 1: E2122-2126.

141. Metzger-Filho O, Tutt A, de Azambuja E, Saini KS, Viale G, et al. (2012) Dissecting the heterogeneity of triple-negative breast cancer. J Clin Oncol 30: 1879-1887.

142. Hurvitz S, Mead M (2016) Triple-negative breast cancer: advancements in characterization and treatment approach. Curr Opin Obstet Gynecol 28: 59-69. [Crossref]

143. Charafe-Jauffret E, Ginestier C, Iovino F, Wicinski J, Cervera N, et al. (2009) Breast cancer cell lines contain functional cancer stem cells with metastatic capacity and a distinct molecular signature. Cancer Res 69: 1302-1313.

144. Rappa G, Lorico A (2010) Phenotypic characterization of mammosphere-forming cells from the human MA-11 breast carcinoma cell line. Exp Cell Res 316: 15761586. [Crossref]

145. Ablett MP, Singh JK, Clarke RB (2012) Stem cells in breast tumours: are they ready for the clinic? Eur J Cancer 48: 2104-2116. [Crossref]

146. Lawson DA, Bhakta NR, Kessenbrock K, Prummel KD, et al. (2015) Single-cel analysis reveals a stem-cell program in human metastatic breast cancer cells. Nature 526: 131-135. [Crossref]

147. Ning X, Shu J, Du Y, Ben Q, Li Z (2013) Therapeutic strategies targeting cancer stem cells. Cancer Biol Ther 14: 295-303. [Crossref]

148. Wang T,2, Shigdar S2, Gantier MP3,4, et al. (2015) Cancer stem cell targeted therapy: progress amid controversies. Oncotarget 6: 44191-44206. [Crossref] 
149. Calugaru V, Nauraye C, Noël G, Giocanti N, Favaudon V, et al. (2011) Radiobiological characterization of two therapeutic proton beams with different initial energy spectra used at the Institut Curie Proton Therapy Center in Orsay. Int J Radiat Oncol Biol Phys 81:1136-1143.

150. Durante M (2014) New challenges in high-energy particle radiobiology. Br J Radiol 87: 20130626. [Crossref]

151. Akamatsu H, Karasawa K, Omatsu T, Isobe Y, Ogata R, et al. (2014) First experience of carbon-ion radiotherapy for early breast cancer. Jpn J Radiol 32: 288-295. [Crossref]

152. Ferlay J, Soerjomataram I, Dikshit R, Eser S, Mathers C, et al. (2015) Cancer incidence and mortality worldwide: sources, methods and major patterns in GLOBOCAN 2012. Int J Cancer 136: E359-E386.

153. Siegel RL, Miller KD, Jemal A (2016) Cancer statistics. CA Cancer J Clin 2016: 7-30.

154. Hohenberger W, Weber K, Matzel K, Papadopoulos T, Merkel S. (2009) Standardized surgery for colonic cancer: complete mesocolic excision and central ligationtechnical notes and outcome. Colorectal Dis 11:354-364.

155. Rödel C, Graeven U, Fietkau R, Hohenberger W, Hothorn T, et al. (2015) Oxaliplatin added to fluorouracil-based preoperative chemoradiotherapy and postoperative chemotherapy of locally advanced rectal cancer (the German CAO/ARO/AIO-04 study): final results of the multicentre, open-label, randomised, phase 3 trial. Lancet Oncol 16: 979-989.

156. Siegel RL, Miller KD, Jemal A (2015) Cancer statistics, 2015. CA Cancer J Clin 65: 5-29.

157. De Vita F, Ventriglia J, Febbraro A, Laterza MM, Fabozzi A, et al. (2016) NABpaclitaxel and gemcitabine in metastatic pancreatic ductal adenocarcinoma (PDAC): from clinical trials to clinical practice. BMC Cancer 16: 709. [Crossref]

158. Malvezzi M, Bertuccio P, Levi F, La Vecchia C, Negri E (2013) European cancer mortality predictions for the year 2013. Ann Oncol 24: 792-800. [Crossref]

159. Scheithauer W, Ramanathan RK, Moore M, Macarulla T, Goldstein D, et al. (2016) Dose modification and efficacy of nab-paclitaxel plus gemcitabine vs. gemcitabine for patients with metastatic pancreatic cancer: phase III MPACT trial. J Gastrointest Oncol 7: 469-478.

160. Li C, Heidt DG, Dalerba P, Burant CF, Zhang L, et al. (2007) Identification of pancreatic cancer stem cells. Cancer Res 67: 1030-1037. [Crossref]

161. Li C, Lee CJ, Simeone DM (2009) Identification of human pancreatic cancer stem cells. Methods Mol Biol 568: 161-173. [Crossref]

162. Firsanov DV, Solovjeva LV, Svetlova MP (2011) H2AX phosphorylation at the sites of DNA double-strand breaks in cultivated mammalian cells and tissues. Clin Epigenetics 2: 283-297.

163. Mah LJ, Vasireddy RS, Tang MM, Georgiadis GT, El-Osta A, et al. (2010) Quantification of gammaH2AX foci in response to ionising radiation. J Vis Exp 38: 1957.

164. Bracalente C, Ibañez IL, Molinari B, Palmieri M, Kreiner A, et al. (2013) Induction and persistence of large ?H2AX foci by high linear energy transfer radiation in DNAdependent protein kinase-deficient cells. Int J Radiat Oncol Biol Phys 87: 785-794.

165. van Oorschot B, Hovingh S, Dekker A, Stalpers LJ, Franken NA (2016) Predicting Radiosensitivity with Gamma-H2AX Foci Assay after Single High-Dose-Rate and Pulsed Dose-Rate Ionizing Irradiation. Radiat Res 185: 190-198.
166. Takahashi M, Hirakawa H, Yajima H, Izumi-Nakajima N, Okayasu R, et al. (2014) Carbon ion beam is more effective to induce cell death in sphere-type A172 human glioblastoma cells compared with X-rays. Int J Radiat Biol 90: 1125-1132. [Crossref]

167. Kamlah F, Hänze J, Arenz A, Seay U, Hasan D, et al. (2011) Comparison of the effects of carbon ion and photon irradiation on the angiogenic response in human lung adenocarcinoma cells. Int J Radiat Oncol Biol Phys 80: 1541-1549.

168. Menegakis A, Yaromina A, Eicheler W, Dörfler A, Beuthien-Baumann B, et al. (2009) Prediction of clonogenic cell survival curves based on the number of residual DNA double strand breaks measured by gammaH2AX staining. Int J Radiat Biol 85: 1032 1041. [Crossref]

169. Cojoc M, Mäbert K, Muders MH, Dubrovska A (2015) A role for cancer stem cells in therapy resistance: cellular and molecular mechanisms. Semin Cancer Biol 31 : 16-27. [Crossref]

170. Gottesman MM, Fojo T, Bates SE (2002) Multidrug resistance in cancer: role of ATPdependent transporters. Nat Rev Cancer 2: 48-58. [Crossref]

171. An Y, Ongkeko WM (2009) ABCG2: the key to chemoresistance in cancer stem cells? Expert Opin Drug Metab Toxicol 5: 1529-1542. [Crossref]

172. Vasiliou V, Vasiliou K, Nebert DW (2009) Human ATP-binding cassette (ABC) transporter family. Hum Genomics 3: 281-290. [Crossref]

173. Huang W-C, Hsieh Y-L, Hung C-M, Chien P-H, Chien Y-F, et al. (2013) BCRP/ ABCG2 inhibition sensitizes hepatocellular carcinoma cells to sorafenib. PLoS One 8: e83627.

174. Lecerf-Schmidt F, Peres B, Valdameri G, Gauthier C, Winter E, et al. (2013) ABCG2 recent discovery of potent and highly selective inhibitors. Future Med Chem 5: 1037 1045. [Crossref]

175. Stacy AE, Jansson PJ, Richardson DR (2013) Molecular pharmacology of ABCG2 and its role in chemoresistance. Mol Pharmacol 84: 655-669. [Crossref]

176. Hatefi N, Nouraee N, Parvin M, Ziaee SA, Mowla SJ (2012) Evaluating the expression of oct4 as a prognostic tumor marker in bladder cancer. Iran J Basic Med Sci 15: 1154-1161. [Crossref]

177. White E (2015) The role for autophagy in cancer. J Clin Invest 125: 42-46. [Crossref]

178. Liu X, Fan D (2015) The epithelial-mesenchymal transition and cancer stem cells functional and mechanistic links. Curr Pharm Des 21: 1279-1291. [Crossref]

179. Oike T, Sato H, Noda SE, Nakano T (2016) Translational research to improve the efficacy of carbon ion radiotherapy: Experience of Gunma University. Front Oncol 6: 139 .

180. Huynh TT, Lin CM, Lee WH, Wu AT, Lin YK, et al. (2015) Pterostilbene suppressed irradiation-resistant glioma stem cells by modulating GRP78/miR-205 axis. $J$ Nutr Biochem 26: 466-475.

181. Moncharmont C, Levy A, Guy JB, Falk AT, Guilbert M, et al. (2014) Radiationenhanced cell migration/invasion process: a review. Crit Rev Oncol Hematol 92: 133-142. [Crossref]

182. Sai S, Oonishi K, Mori M, Kamijo T, Yamada S, et al. (2012) The Role of XRCC4 in sensitizing human colon cancer stem-like cells to X-ray or carbon ion beam. Int $J$ Radiat Oncol Biol Phys 84: S685.

183. Seshacharyulu P, Baine MJ, Souchek JJ, Menning M, Kaur S, et al. (2017) Biological determinants of radioresistance and their remediation in pancreatic cancer. Biochim Biophys Acta 1868: 69-92.

Copyright: (C2017 Liu MT. This is an open-access article distributed under the terms of the Creative Commons Attribution License, which permits unrestricted use, distribution, and reproduction in any medium, provided the original author and source are credited. 